Article

\title{
Tensile and Compressive Behavior in the Experimental Tests for PLA Specimens Produced via Fused Deposition Modelling Technique
}

\author{
Salvatore Brischetto *(D) and Roberto Torre $(\mathbb{D})$ \\ Department of Mechanical and Aerospace Engineering, Politecnico di Torino, Corso Duca degli Abruzzi 24, \\ 10129 Torino, Italy; roberto.torre@polito.it \\ * Correspondence: salvatore.brischetto@polito.it; Tel.: +39-011-090-6813; Fax: +39-011-090-6899
}

Received: 31 August 2020; Accepted: 16 September 2020 ; Published: 18 September 2020

\begin{abstract}
In this paper, polymeric specimens are produced via the Fused Deposition Modelling (FDM) technique. Then, experimental tensile and compression tests are conducted to evaluate the main mechanical properties of elements made of PolyLacticAcid (PLA) material. A standardized characterization test method for FDM 3D printed polymers has not been developed yet. For this reason, the ASTM D695 (usually employed for polymers produced via classical methods) has been here employed for FDM 3D printed polymers after opportune modifications suggested by appropriate experimental checks. A statistical analysis is performed on the geometrical data of the specimens to evaluate the machine process employed for the 3D printing. A capability analysis is also conducted on the mechanical properties (obtained from the experimental tests) in order to calculate acceptable limits useful for possible structural analyses. The Young modulus, the proportional limit and the maximum strength here defined for PLA specimens allow to confirm the different behavior of FDM printed PLA material in tensile and compressive state. These differences and the calculated acceptable limits for the found mechanical properties must be considered when this technology will be employed for the design of small structural objects made of PLA, as in the present study, or ABS (Acrilonitrile Butadiene Stirene). From the statistical and capability analysis, the employed printing process appears as quite stable and replicable. These types of research together with other similar ones that will be conducted in the future will allow to use polymeric materials and the FDM technique to produce small structural elements and also to carry out the appropriate verifications.
\end{abstract}

Keywords: Fused Deposition Modelling (FDM); PolyLacticAcid (PLA); tensile tests; compression tests; experimental tests; capability analysis; statistical analysis.

\section{Introduction}

In the recent years, several researchers have been worked on additive technologies and studied the effects of processing parameters on the mechanical properties of 3D printed specimens. As the mechanical properties of FDM printed polymeric structures are intrinsically low, these researches aim to improve printed components by working on processing parameters and on additive typologies. Mechanical properties of 3D printed elements, made of polymeric materials (such as the Acrylonitrile Butadiene Styrene (ABS) and the PolyLactic Acid (PLA)) and produced via the Fused Deposition Modelling (FDM) technique, are not apriori known because the raw polymeric filaments undergo various transformations during the printing process; for example, they are melted, dropped and then spread on a printing plane. In order to correctly evaluate the mechanical properties of 3D printed polymeric elements, they must be evaluated in a systematic way by also defining the possible statistical limits. The aim of the present paper is to explore the tensile and compressive performances of 3D FDM 
printed elements made of PLA in order to evaluate its mechanical behavior and to explore its potential for future structural applications.

Additive Manufacturing (AM) processes are usually based on the production of layer-by-layer elements, a classification was proposed in Levy et al. [1] where different materials and production techniques were shown. AM methodology was patented in 1984, in particular SLA (Stereolithography) technology for resins. AM technologies for powders and wires were introduced later. In classical production procedures, the material is subtracted from a raw part. The brilliant future of AM technology was discussed in Lu et al. [2] where its enormous potential was clearly indicated and several applications were shown. Carlier et al. [3] proposed a study to investigate the possibility to produce implantable devices via the 3D FDM technology. The physical properties of these elements were difficult to be determined and they depended on the deposition temperature, deposition rate and layer thickness used in the printing process. Other important biomedical applications of 3D printing technologies can be found on the works of Raj et al. [4] and Mohd Pu'ad et al. [5]. The difficulties in the determination of correct mechanical properties of polymeric elements printed via AM were also discussed on the works of Dana et al. [6], Jiang et al. [7] and Elmrabet and Siegkas [8]. These properties must be defined using opportune tests such as tensile, bending, compression, fatigue and impact tests [9]. The most important conditions to produce elements via 3D printing processes were discussed on the work of Duty et al. [10]. In the work of El Moumen et al. [11], the effect of pores formation on the mechanical properties of 3D printed polymeric elements was investigated. This study was conducted using the homogenization technique based on the RVE (Representative Volume Element) notion. Gebisa and Lemu [12] demonstrated that the process parameters influence the tensile properties of high-performance ULTEM 9085 polymeric material printed via 3D FDM technique. Harshitha and Rao [13] combined PLA and ABS for the 3D FDM printing of a nut and a bolt, the structural analysis was performed using the ANSYS commercial code. The PLA as well as ABS bolts were correlated with each other and evaluated. FDM and conventional injection molding techniques were employed to produce elements made of PLA, ABS or Nylon 6 in [14]. Then, these elements were compared in terms of physical and mechanical characteristics. The proposed results can provide a guide to manufacturing the final products using FDM with the desired performance. In [15], 3D FDM printed bi-material laminates made of PLA and PLA Carbon Black (PLA CB) (using different raster orientations) were investigated and the mechanical behaviour was analyzed via the Classical Lamination Theory (CLT). In [16], the FDM technique was also applied to continuous fiber reinforced thermoplastic composites and an innovative extruder for the FDM process was developed. Parandoush and Lin [17] and Popescu et al. [18] wrote useful review papers about the different printing methods such as Fused Deposition Modelling (FDM), Laminated Object Manufacturing (LOM), StereoLithography (SL) and Extrusion and Selective Laser Sintering (SLS). They also underlined practical and useful features, key process parameters and limitations, common and real applications. Readers can refer to these review articles for further insights on the subject. FDM technology combined with the use of PLA and ABS is very common in the literature because these polymeric materials are particularly suitable for being produced with this type of additive manufacturing technology. An innovative experimental method was shown in [19] to investigate how the printing factors influence the mechanical properties of the produced elements. Semi-analytical, numerical and experimental methods was used in [20] to investigate the mechanical properties of 3D printed sandwich panels when the weight was reduced. PLA elements produced via high density $3 \mathrm{D}$ printing method could have an orthotropic elasto-plastic response which was characterised by a strong tension-compression asymmetry. This feature was developed in [21] where the investigated material was tougher in the extrusion direction than in the transverse direction. Another possibility was the carbon fiber reinforced polymer sandwich structures printed by means of the 3D technology [22] and embedding cores having different shapes such as honeycomb, rhombus, rectangle or circle ones. Three-point bending tests were performed to investigate how the maximum load and the flexural modulus increased when the core density also increased. In [23], these thermoplastic composites were classified 
as particle-, fiber-, nanomaterial-based composites and polymer blends; for all these configurations, the increasing of the FDM temperature could give benefits in terms of printing characteristics. However, the mechanical properties of printed pure polymeric elements remain low and there is an important necessity to develop new printed polymer composites having higher performances [24]. For these reasons, Yadav et al. [25] analyzed how the main FDM parameters influenced the tensile strength of ABS, PETG and multi-materials constituted by ABS and PETG. The main investigated parameters were extrusion temperature, layer thickness and material density. A similar topic was investigated in [26] where the ultimate tensile strength of FDM printed PLA elements was analyzed via both theoretical models and experimental tests to see the effects of the printing angles. The tensile strength and Young modulus of PLA elements produced via 3D FDM printing were determined in [27] as functions of printing angle and layer thickness. Two innovative theoretical models were employed, the first model was based on transversely isotropic material hypothesis and Tsai-Hill strength criterion, the second one was based on orthotropic material hypothesis and plane stress state conditions. Afrose et al. [28] proposed a study about the fatigue characteristics of PLA parts processed through FDM. Similar studies about the fatigue behavior of polymeric FDM printed parts were also proposed in $[29,30]$. Torres et al. [31] investigated the influences of printing parameters on the material properties of FDM printed PLA components tested in torsion. The work of Berzal et al. [32] applied the finite element methodology to analyze the mechanical behaviour of PLA parts produced via fused deposition with a 3D printer. The most accurate way to model the actual response of PLA parts in a torsion test was shown.

Structural objects made of polymeric materials and produced via Fused Deposition Modelling (FDM) technology are not so common in the literature because of the difficulty to evaluate the mechanical properties of these parts. Selective Laser Sintering (SLS) is usually much more used to produce structural elements. In [33], the Selective Laser Sintering (SLS) and the Fused Deposition Modelling (FDM) methodologies were deeply discussed, these technologies are based on the Computer Aided Design (CAD). Finite Element, analytical and experimental methods (opportunely combined as discussed in [34]) are fundamental to show the main advantages given by 3D printing processes when they are employed for the production of advanced systems and structures in important fields such as aerospace, mechanical, civil and biomedical engineering ones. In [35], the SLS was used for the manufacturing of a metallic multifunctional sandwich panel including a trabecular core. It was used as a valid alternative to classical de-icing and anti-icing systems of recent aircrafts in order to obtain significant advantages in terms of performances and weight reduction. From the comparison between SLS and FDM technologies, it is clear how the last one is not usually used to produce structural elements because of the difficulties in the determination of their mechanical properties. For this reason, in recent years, the present authors worked to improve this feature and important studies were performed for FDM printed elements made of ABS and PLA. The idea was to use these materials and the FDM method for the production of small structural elements when they are subjected to low load levels as in the case of the design and FDM manufacturing of a small multipurpose modular drone made of PLA [36,37]. This drone, known as PoliDrone, has been patented in 2018 [38]. The SLS technology cannot be applied to this project for economical and weight increasing reasons.

The most recent works of the present authors about the use of FDM method for the production of structural elements made of PLA and/or ABS are here discussed to better understand the collocation of the present paper. Brischetto et al. [39] analyzed the compression behavior of FDM printed ABS specimens by investigating the ultimate static compression stress and the opportune slenderness ratio to avoid the buckling phenomenon. Experimental tests on FDM produced specimens made of ABS and PLA were conducted in [40] to perform their mechanical characterization using a possible analogy with unidirectional long fiber reinforced composites. In this way, the orthotropic behavior hypothesis could be used to determine the nine basic engineering constants to define the 3D matrix of elastic coefficients; this matrix could be useful for the Finite Element analysis of structural parts of a small 3D printed drone. In order to correctly perform the experimental mechanical characterization 
of FDM printed ABS and PLA specimens, it is important to evaluate the machine process in terms of statistical parameters as given in [41]. In [42,43], different sandwich configurations were preliminary investigated; homogenous and honeycomb cores were printed and PLA and/or ABS were used for the core and for the skins. In these preliminary analyses, the honeycomb sandwich specimens with core and skins made of the same PLA were identified as the most promising configuration in terms of mechanical performances and weight reduction ratio.

The present paper proposes tensile and compression experimental tests for FDM printed specimens made of PLA in order to evaluate the main mechanical properties such as the linear Young modulus, the linear elastic limit stress (or proportional limit) and the ultimate tensile strength. For each mechanical property, statistical and capability analyses are performed by means of a normal Gaussian distribution in order to determine an appropriate range for the design values. The geometrical parameters of each specimen have been measured and evaluated from a statistical point of view in order to analyze the machine process stability. The study of the mechanical properties has been performed to understand the process parameter effects and to remark the differences between the tensile and compressive states. The work is organized in the following way: Section 2 is devoted to the description of produced specimens and the collection of their geometrical data; experimental tests are described in Section 3 where the main mechanical parameters for tensile and compressive behavior are collected; statistical and capability analysis for geometrical data and mechanical properties of compression and tensile tests is shown in Section 4; the main conclusions are given in Section 5.

\section{Production of Specimens and Geometrical Data}

Both specimen types for tensile and compression tests were made of the same black PolyLactic Acid-PLA (produced by Shenzhen Eryone Technology Co., Ltd., Shenzhen, China) and they were produced via the 3D Fused Deposition Modelling (FDM) technique. A professional 3D printer was employed for the production of both specimens for compression and tensile tests, it was the Funmat HT (this 3D printer is based on the Fused Filament Fabrication (FFF) technology which is often also called FDM, even if this last one is sometimes considered as a peculiarity of the Stratasys devices). The tensile specimens had the typical dog bone shape and the compression specimens were parallelepipeds with a square cross section and an opportune length in order to avoid buckling phenomena (see the Standard references ASTM D638 [44] and ASTM D695 [45] for tensile and compressive tests, respectively).

\subsection{Specimens for Tensile Test}

The specimens for tensile tests had the shape and the main geometrical dimensions as indicated in Figure 1. The 3D CAD draw was converted in the STL (Standard Triangulation Language) format. In it, each external and internal surface was described with an opportune number of triangles. The slicing operation allowed the conversion of the file STL in a Gcode format in order to give the main instructions to the Funmat HT printer for the production process. As clearly indicated in Figure 2, the printing plane was the $x y$ one and the layers were summed along the $z$ direction; therefore, the printing direction was the $x$ one with raster angle orientation sequence equals $\pm 45^{\circ}$ in order to have a criss-cross sequence with rectilinear infill. This choice should give a quasi-isotropic behavior although small additional shear stresses may occur due to some small differences between the various deposited layers. The production of the 12 specimens was performed printing 6 specimens at the time in two different moments. Each family belongs to two different printing sets. This grouping could have repercussions on the geometrical and mechanical data as will be demonstrated in the following sections. The main printing data $[37,40]$ were: the first layer thickness equals $0.2 \mathrm{~mm}$, the thickness of the further layers equals $0.1 \mathrm{~mm}$, a number of perimeter beads equals 1 and infill density equals $100 \%$ with a rectilinear fill pattern. The infill speed was $30 \mathrm{~mm} / \mathrm{s}$. The extruder temperature for the first layer was $215^{\circ} \mathrm{C}$, it became $210{ }^{\circ} \mathrm{C}$ for the other layers. The bed temperature for the first layer and the subsequent printed layers was imposed equal to $30^{\circ} \mathrm{C}$. 


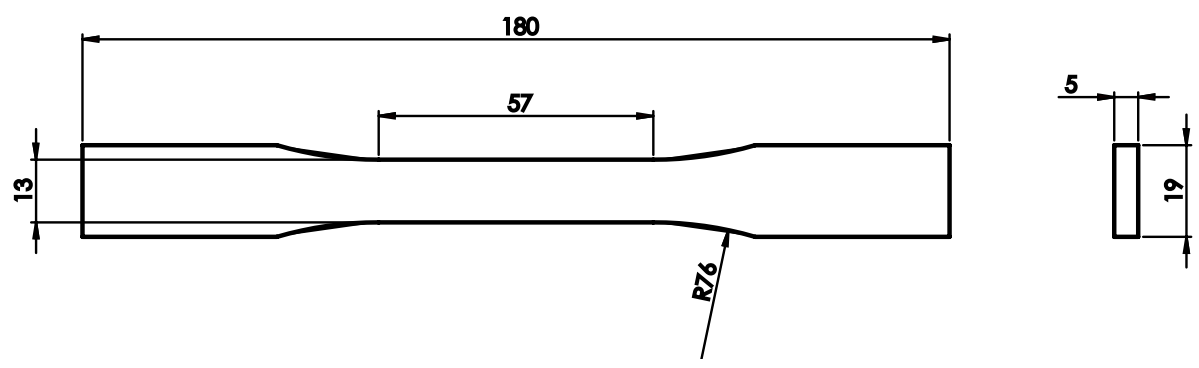

Figure 1. Geometrical data (in millimeters) of the dog bone specimen for tensile tests.

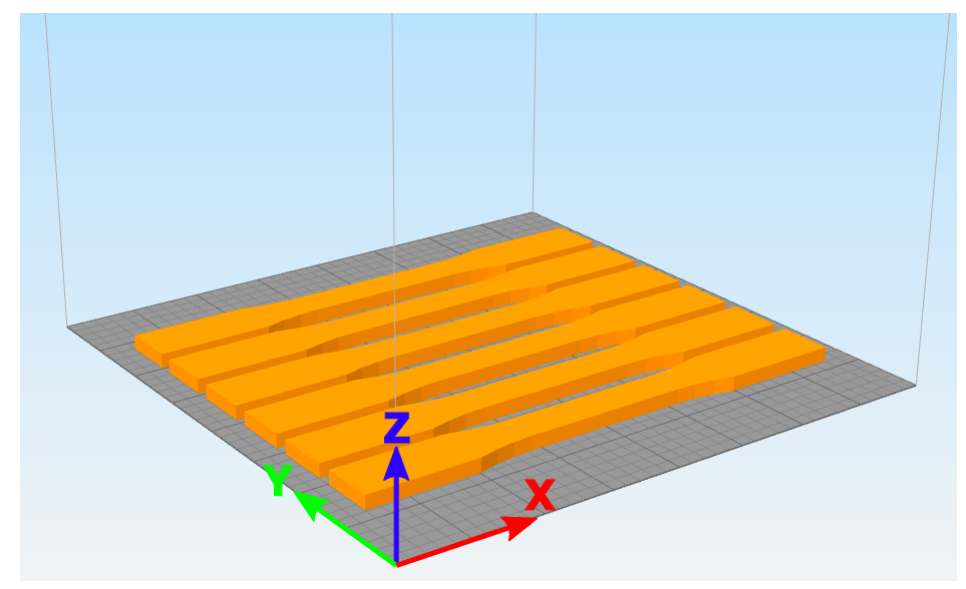

Figure 2. Printing plane for dog bone specimens for tensile tests.

From Figure 1, the nominal or target geometrical data were: overall length of the specimen in the $x$ direction equals $180 \mathrm{~mm}$, length of the reduced section in the $x$ direction equals $57 \mathrm{~mm}$, reduced section width in $y$ direction equals $13 \mathrm{~mm}$, thickness of the specimen in the $z$ direction equals $5 \mathrm{~mm}$. The target value for the weight was $18.18 \mathrm{~g}$ and it was obtained by considering the volume of the specimen as given by the CAD model, and then multiplying it for the infill density equals 1 and for the mass density of the PLA equals $1.25 \mathrm{~g} / \mathrm{cm}^{3}$. The real geometrical data for each produced specimen were measured by means of a digital caliper, the weight of each specimen was determined using a digital weight scale. The real data and the target or nominal values were given in Table 1 where the 12 specimens were divided in two families composed of 6 specimens per each one (see the first column). It was not possible to correctly measure the length of the reduced section in the $x$ direction by means of the digital caliper because of the presence of the curvature, in this case we had only the target value given in the last line of the second column. The target values for each geometrical dimension were always given in the last line. The third column gives the measured width of the reduced section in the $y$ direction. The fourth column shows the measured values for the thickness of the specimens in the $z$ direction. The fifth column gives the weight of each specimen as determined by means of the digital weight caliber. Finally, the last column gives the mass density obtained as the weight divided for the target value $V=14.541 \mathrm{~cm}^{3}$ of the volume as given by the software employed for the CAD draw (this choice is due to the complexity of the geometry of the dog bone specimen which makes it impossible to define its actual volume through true measurements). Therefore, the weight and mass density are proportional by means of a constant such as the volume $V$. For this reason, the statistical and capability analyses for the weight and the mass density are coincident and we will show only the first one. 
Table 1. Measured geometrical data, weights and mass densities for the 12 produced specimens (divided in two families) for tensile tests.

\begin{tabular}{cccccc}
\hline Specimen (Family) & $\mathbf{X}[\mathbf{m m}]$ & $\mathbf{Y}[\mathbf{m m}]$ & $\mathbf{Z}[\mathbf{m m}]$ & $\mathbf{W}[\mathbf{g}]$ & $\rho\left[\mathrm{g} / \mathrm{cm}^{\mathbf{3}}\right]$ \\
\hline $1(1)$ & - & 13.00 & 4.96 & 18.09 & 1.244 \\
$2(1)$ & - & 13.00 & 4.93 & 18.05 & 1.241 \\
$3(1)$ & - & 13.01 & 4.93 & 17.97 & 1.236 \\
$4(1)$ & - & 13.07 & 4.96 & 18.11 & 1.245 \\
$5(1)$ & - & 13.02 & 4.98 & 18.05 & 1.241 \\
$6(1)$ & - & 13.04 & 4.92 & 18.12 & 1.246 \\
$7(2)$ & - & 13.01 & 4.93 & 17.94 & 1.234 \\
$8(2)$ & - & 12.96 & 4.92 & 18.00 & 1.238 \\
$9(2)$ & - & 13.00 & 4.88 & 17.86 & 1.228 \\
$10(2)$ & - & 13.01 & 4.91 & 17.92 & 1.232 \\
$11(2)$ & - & 12.97 & 4.92 & 17.82 & 1.226 \\
$12(2)$ & - & 13.02 & 4.89 & 17.96 & 1.235 \\
\hline TARGET & $\mathbf{5 7 . 0 0}$ & $\mathbf{1 3 . 0 0}$ & $\mathbf{5 . 0 0}$ & $\mathbf{1 8 . 1 8}$ & $\mathbf{1 . 2 5 0}$ \\
\hline
\end{tabular}

The geometrical data and the weight values shown in Table 1 will be used in Section 4 in order to perform a capability and statistical analysis useful to investigate the process machine stability.

\subsection{Specimens for Compression Test}

The specimens for compression tests had the shape and the main geometrical dimensions as indicated in Figure 3. The 3D CAD draw was converted in the STL format. The parallelepiped-shape specimen had 6 faces and for each face two triangles were sufficient to describe all the internal and external surfaces. Therefore, 12 triangles were enough for the triangulation of the entire parallelepiped-shape specimen. The slicing operation allowed the conversion of the STL file in a Gcode format in order to give the main instructions to the Funmat HT printer for the production process. As clearly indicated in Figure 4, the printing plane was the $x y$ one and the layers were summed along the $z$ direction; the same $\pm 45^{\circ}$ criss-cross sequence with rectilinear infill already employed for specimens for tensile tests was here used. The 12 specimens were printed in two different periods by giving two families composed by 6 specimens per each one. The main printing data were the same already seen for specimens for tensile tests, the only difference was for the perimeter beads [37,39]. In the present case, no perimeter beads were used because of the simplicity of the geometry and also to avoid unwanted reinforcement phenomena in the compression direction.
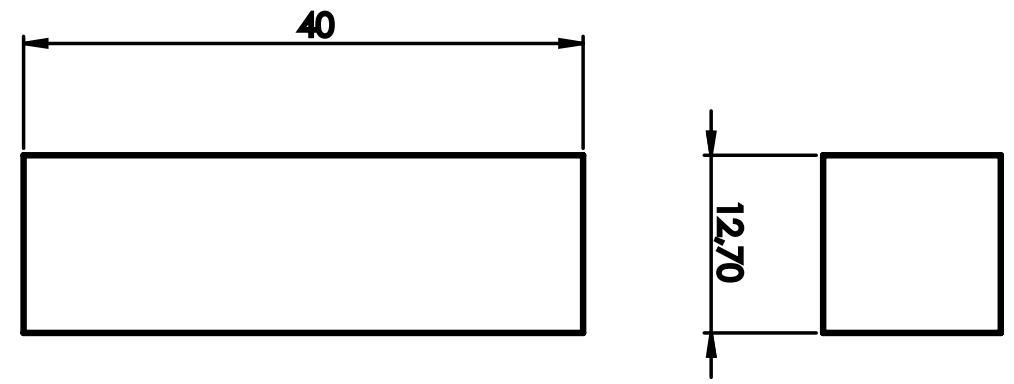

Figure 3. Geometrical data (in millimeters) of the parallelepiped-shaped specimen for the compression tests. 


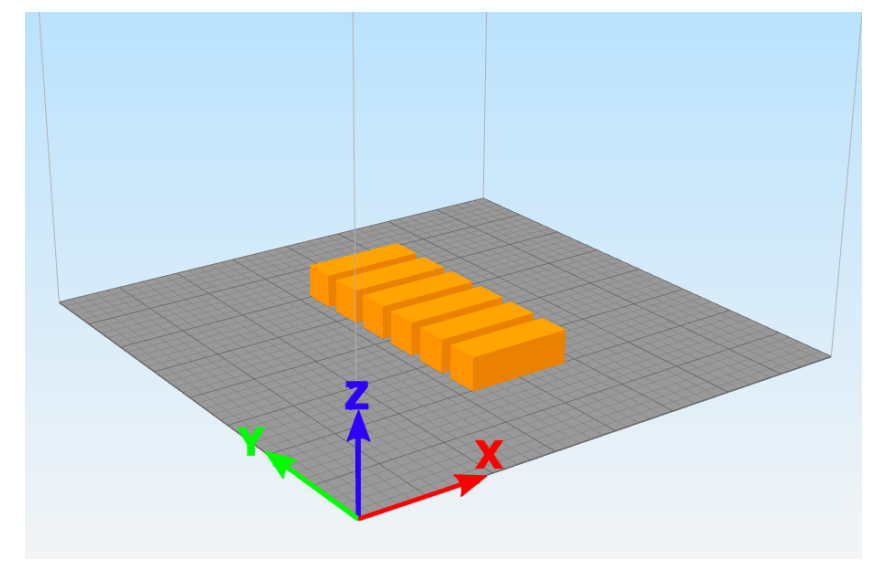

Figure 4. Printing plane for parallelepiped-shaped specimens for compression tests.

From Figure 3, the nominal or target geometrical data were: overall length of the specimen in the $x$ direction equals $40 \mathrm{~mm}$, dimensions of the square cross section were $12.7 \mathrm{~mm}$ in both directions $y$ and $z$. The target value for the weight was $8.06 \mathrm{~g}$ and it was obtained by considering the volume of the specimen (as given by the CAD model) multiplied for the infill density (equals 1) and for the mass density of the PLA equals $1.25 \mathrm{~g} / \mathrm{cm}^{3}$. The real geometrical data for each produced specimen were measured by means of a digital caliper and the weight of each specimen was determined using a digital weight scale. The real data and the target or nominal values are given in Table 2 where the 12 specimens were divided in two families composed of 6 specimens per each one (see the first column). The target values are always given in the last line of the table. The second column shows the length of the specimens in the $x$ direction. The third column gives the measured width of the cross section in the $y$ direction. The fourth column gives the measured width of the cross section in the $z$ direction. The fifth column gives the weight of each specimen determined by using the digital weight caliber. The last column gives the mass density calculated as the weight divided for the nominal volume $V=6.452 \mathrm{~cm}^{3}$ as given by the software for the CAD draw. The capability and statistical information given by the mass density are the same that will be provided by the weight study for the reasons already explained in the section about the specimens for tensile tests.

Table 2. Measured geometrical data and weights for the 12 produced specimens (divided in two families) for compression tests.

\begin{tabular}{cccccc}
\hline Specimen (Family) & $\mathbf{X}[\mathbf{m m}]$ & $\mathbf{Y}[\mathbf{m m}]$ & $\mathbf{Z}[\mathbf{m m}]$ & $\mathbf{W}[\mathbf{g}]$ & $\rho\left[\mathbf{g} / \mathbf{c m}^{\mathbf{3}}\right]$ \\
\hline $1(1)$ & 39.75 & 12.46 & 12.56 & 7.73 & 1.198 \\
$2(1)$ & 39.77 & 12.49 & 12.58 & 7.77 & 1.204 \\
$3(1)$ & 39.78 & 12.45 & 12.56 & 7.72 & 1.197 \\
$4(1)$ & 39.80 & 12.49 & 12.59 & 7.77 & 1.204 \\
$5(1)$ & 39.84 & 12.49 & 12.63 & 7.73 & 1.198 \\
$6(1)$ & 39.80 & 12.43 & 12.60 & 7.68 & 1.190 \\
$7(2)$ & 39.84 & 12.55 & 12.63 & 7.77 & 1.204 \\
$8(2)$ & 39.79 & 12.55 & 12.62 & 7.79 & 1.207 \\
$9(2)$ & 39.79 & 12.52 & 12.59 & 7.76 & 1.203 \\
$10(2)$ & 39.84 & 12.49 & 12.61 & 7.74 & 1.200 \\
$11(2)$ & 39.76 & 12.53 & 12.59 & 7.77 & 1.204 \\
$12(2)$ & 39.83 & 12.46 & 12.60 & 7.71 & 1.195 \\
\hline TARGET & $\mathbf{4 0 . 0 0}$ & $\mathbf{1 2 . 7 0}$ & $\mathbf{1 2 . 7 0}$ & $\mathbf{8 . 0 6}$ & $\mathbf{1 . 2 5 0}$ \\
\hline
\end{tabular}

The geometrical data and the weight values shown in Table 2 will be used in Section 4 in order to perform a capability and statistical analysis useful to investigate the process machine stability. 


\section{Experimental Tests and Mechanical Properties}

The tensile test was conducted in accordance with the standard reference ASTM D638 [44] and the compression test was conducted in accordance with the standard reference ASTM D695 [45]. The same test machine was employed in both cases, the two grips used in the tensile test were replaced by two flat plates in the case of the compression tests. Both test types were conducted at constant speed for the movement of the upper crossbar. This crossbar moved upward in the case of the tensile test and downward in the case of the compression test.

\subsection{Results for Tensile Test}

A standardized tensile test method for FDM printed polymers has not been developed yet [37,40]; therefore, the standardized ASTM D638 [44] procedure for classical polymer testing has been used. This standard suggests the use of specimens with a dog bone shape and a constant speed; hence, the speed of $5 \mathrm{~mm} / \mathrm{min}$ was used and the data were acquired using a frequency of $20 \mathrm{~Hz}$. Moreover, the tensile tests were performed with the MTS QTest machine having a $10 \mathrm{kN}$ load cell, where tensile load $P[N]$ and displacement $\Delta L$ of the upper crossbar in [mm] were saved. From these data, it was possible to obtain the stresses $\sigma$ in MPa and the no-dimensional strains $\epsilon$ :

$$
\sigma=\frac{P}{w t}, \quad \epsilon=\frac{\Delta L}{L_{0}}
$$

where $w$ and $t$ are the cross section dimensions of the reduced section, $w$ is the width and it is measured in millimeters in the $Y$ direction, $t$ is the thickness and it is measured in millimeters in the $Z$ direction. Finally, $L_{0}$ is the length of the reduced section in the $X$ direction equals $57 \mathrm{~mm}$ (the target value is employed in this last case because this geometrical data is not easy to be measured via a digital caliper; the other parameters have been measured for each specimen).

Figures 5 and 6 show the stress-strain curves of the performed tensile tests for the first group of six specimens belonging to family 1 and for the second group of six specimens belonging to family 2 , respectively. In each image, the linear elastic Young modulus $E_{\text {lin }}$ in $\mathrm{MPa}$, the maximum stress or ultimate tensile strength $\sigma_{\max }$ in $\mathrm{MPa}$ and the proportional limit stress $\sigma_{\text {pro }}$ in $\mathrm{MPa}$ are clearly indicated. The linear elastic Young modulus $E_{l i n}$ is the proportionality coefficient between stresses and deformations for the linear elastic region. It represents the slope of the linear elastic part and it is calculated through a linear regression as remarked by the black line. The ultimate tensile strength $\sigma_{\max }$ is the maximum stress value tolerable by the specimen before breaking and in the curve it is given by the maximum value reached by the stress on the stress-strain curve. The proportional limit stress $\sigma_{p r o}$ is the value where the stress-strain curve deviates by $5 \%$ from the linear behavior (see the black line to evaluate such a deviation). Above it, the region is nonlinear but still elastic (which means absence of residual deformations).

The mechanical data given by Figures 5 and 6 are summarized in Table 3. The first column shows the tested specimens and the family to which they belong, the second column gives the linear elastic Young modulus for each specimen, the third column indicates the ultimate tensile strength and the last column shows the proportional limit stress. All these data will be employed in Section 4 to perform a statistical and capability analysis in order to evaluate the limits and to give opportune design values, no reference or target values are available in the case of mechanical parameters. 
Table 3. Collected mechanical data obtained from the tensile tests conducted on the two families of specimens.

\begin{tabular}{cccc}
\hline Specimen (Family) & $E_{\text {lin }}[\mathrm{MPa}]$ & $\sigma_{\text {max }}[\mathrm{MPa}]$ & $\sigma_{\text {pro }}[\mathrm{MPa}]$ \\
\hline $1(1)$ & 2554.7 & 63.9 & 50.2 \\
$2(1)$ & 2607.2 & 63.3 & 49.0 \\
$3(1)$ & 2504.2 & 61.7 & 49.3 \\
$4(1)$ & 2430.0 & 61.6 & 49.0 \\
$5(1)$ & 2403.5 & 59.3 & 51.6 \\
$6(1)$ & 2473.5 & 62.8 & 47.8 \\
$7(2)$ & 2661.0 & 58.2 & 43.9 \\
$8(2)$ & 2705.8 & 61.0 & 39.4 \\
$9(2)$ & 2513.3 & 62.8 & 47.9 \\
$10(2)$ & 2668.7 & 59.9 & 43.6 \\
$11(2)$ & 2455.1 & 62.0 & 45.4 \\
$12(2)$ & 2611.4 & 61.4 & 42.5 \\
\hline
\end{tabular}
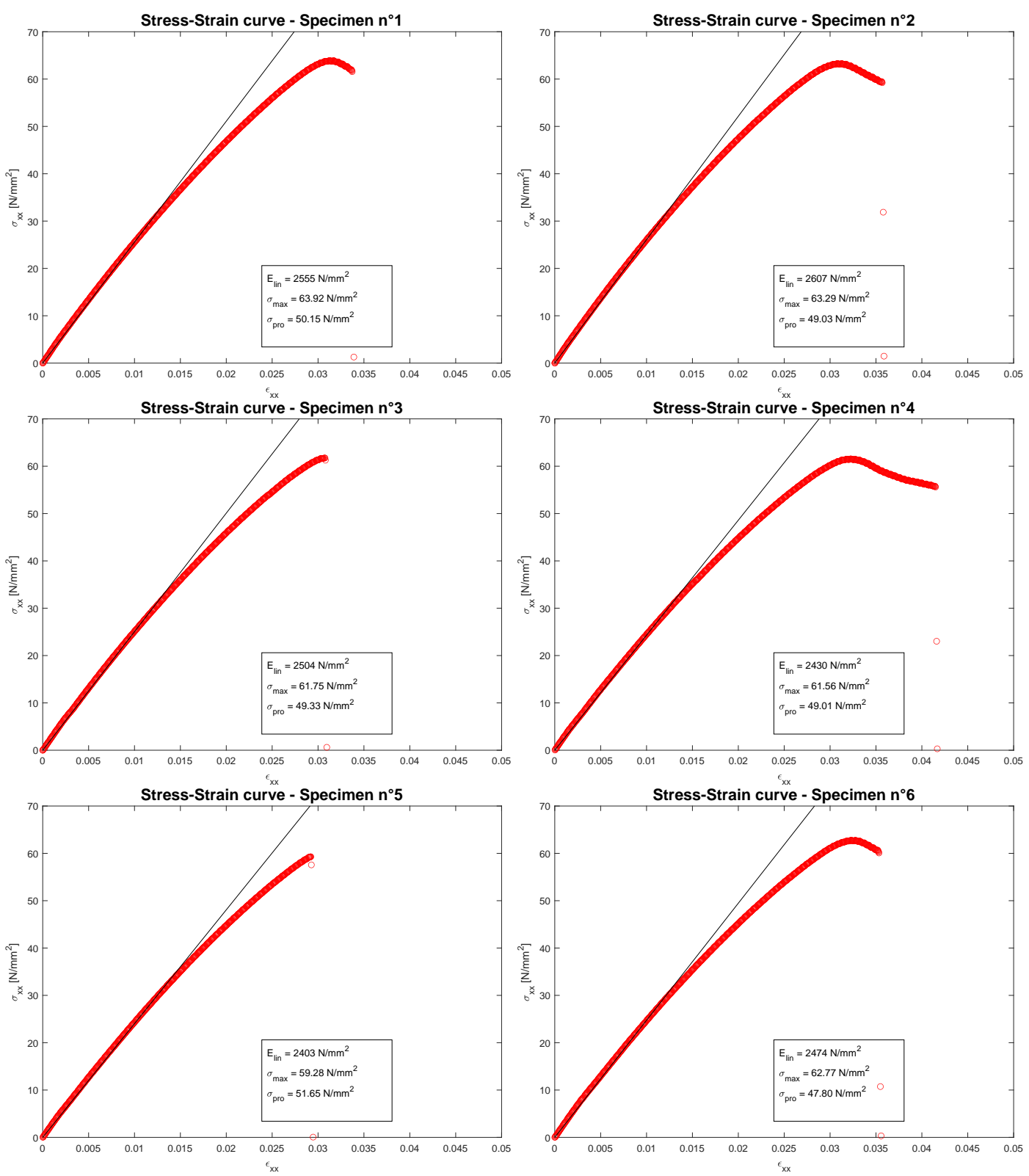

Figure 5. Stress-strain $(\sigma-\epsilon)$ tensile test curves for the first 6 specimens of family 1. 

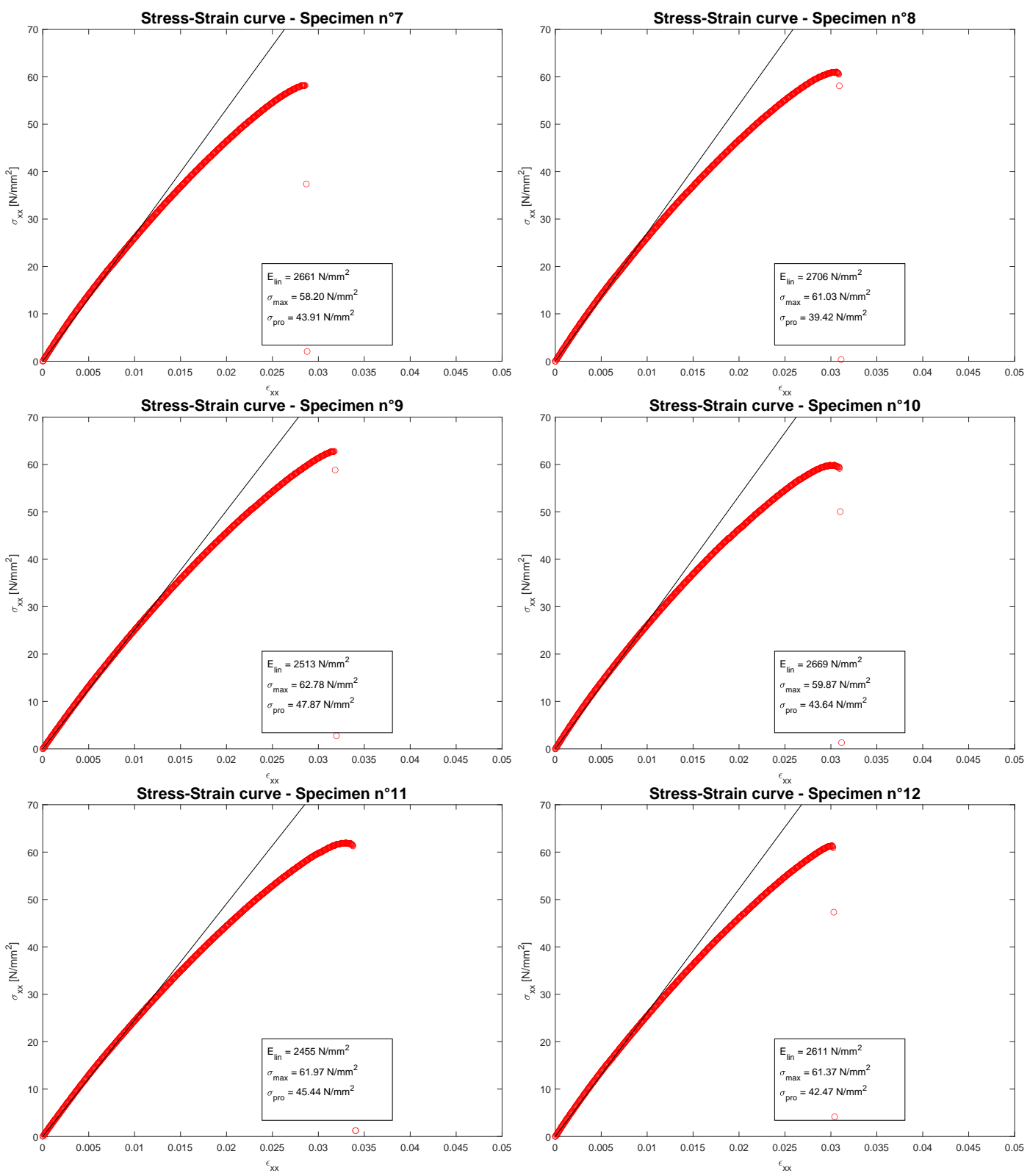

Figure 6. Stress-strain $(\sigma-\epsilon)$ tensile test curves for the second 6 specimens of family 2.

\subsection{Results for Compression Test}

One of the possibilities for the geometry of the tested specimens suggested by the standard reference ASTM D695 [45] is the use of parallelepiped-shaped specimens with a square cross section. A standardized test method for FDM 3D printed polymers has not been developed yet; therefore, the ASTM D695 for classical polymers has been employed [37,39]. A constant speed for the downward movement of the upper crossbar is requested, this speed is here equal to $-1.8 \mathrm{~mm} / \mathrm{min}$ (the reference standard usually suggests $-1.3 \pm 0.3 \mathrm{~mm} / \mathrm{min}$, the actual speed value employed in the present tests is greater in order to correct some problems for data acquisition in the machine used in our department). The frequency of data acquisition is equal to $20 \mathrm{~Hz}$, these data are the applied load $P$ in Newton and the displacement $\Delta L$ of the upper crossbar in millimeters. From these data, it is possible to obtain the stresses $\sigma$ in $\mathrm{MPa}$ and the no-dimensional strains $\epsilon$ by using the same Equation (1) already seen for the tensile test. In the case of the compression test, $w$ is the width in millimeters of the square cross section of each tested specimen in the $Y$ direction, $t$ is the width in millimeters of the square cross section of 
each tested specimen in the $Z$ direction and $L_{0}$ is the length of each specimen in the $X$ direction in millimeters (all these data are the actual values of each specimen).

The slenderness ratio is the ratio between the free length of inflection or effective length of the specimen and the least radius of gyration of its cross section. The standard reference suggests values between 11:1 and 16:1 in order to avoid buckling phenomena. The specimens here printed have a slenderness ratio value roughly equal to 11:1. In fact, the effective length is equal to $40 \mathrm{~mm}$ (the presence of the two plane plates can be considered as simply supported boundary conditions) and the least radius of gyration of a square cross section is equal to $0.289 w$.

Figure 7 shows the stress-strain curves of the performed compression tests for the first group or family, only 5 specimens are given because the test for the first one was not successful and it was considered as failed. Figure 8 shows the stress-strain curves of the performed compression tests for the second group of 6 specimens belonging to family 2 . In each image, only the linear elastic Young modulus $E_{\text {lin }}$ in MPa is given because the tests were stopped when the machine MTS QTest arrived to the maximum applicable load P equals $10 \mathrm{kN}$ (which is the value of the employed load cell). For this applied load, only a linear elastic region is clearly showed and no proportional limit stresses and ultimate tensile strengths can be defined in an appropriate way. The black line represents the linear elastic region and its slope is the linear compression Young modulus obtained from a linear regression. In each image of Figures 7 and 8 , a toe point is clearly shown which is a point with a horizontal tangent between two different linear elastic regions. This toe point is due to a specimen misalignment, which is generated by a slipping in the grips, with a consequent realignment with respect to the load application direction. This phenomenon is a mechanical test characteristic and not a material characteristic. The standard reference ASTM D638 [44] foresees this toe point and it suggests to calculate the linear elastic Young modulus in the linear elastic region after this toe point. For this reason, the black line is drawn parallel to the red curve.

The mechanical data given by Figures 7 and 8 are summarized in Table 4 where only the linear elastic Young modulus for each specimen is proposed in the second column (except for the first one because the first test was not successful and it was considered as failed). The other columns are empty because the ultimate tensile strength and the proportional limit stress cannot be determined for the reasons already explained. All these data will be employed in Section 4 to perform a statistical and capability analysis in order to evaluate the limits and to give opportune design values; no reference or target values are available in the case of mechanical parameters.

The comparison between the linear elastic Young modulus obtained from the tensile test with that obtained from the compressive test remarks the difference of the mechanical behavior between the two states: the tensile and compressive one. This feature is a peculiarity of the FDM printed polymeric elements and it must be always considered in the design approach. 

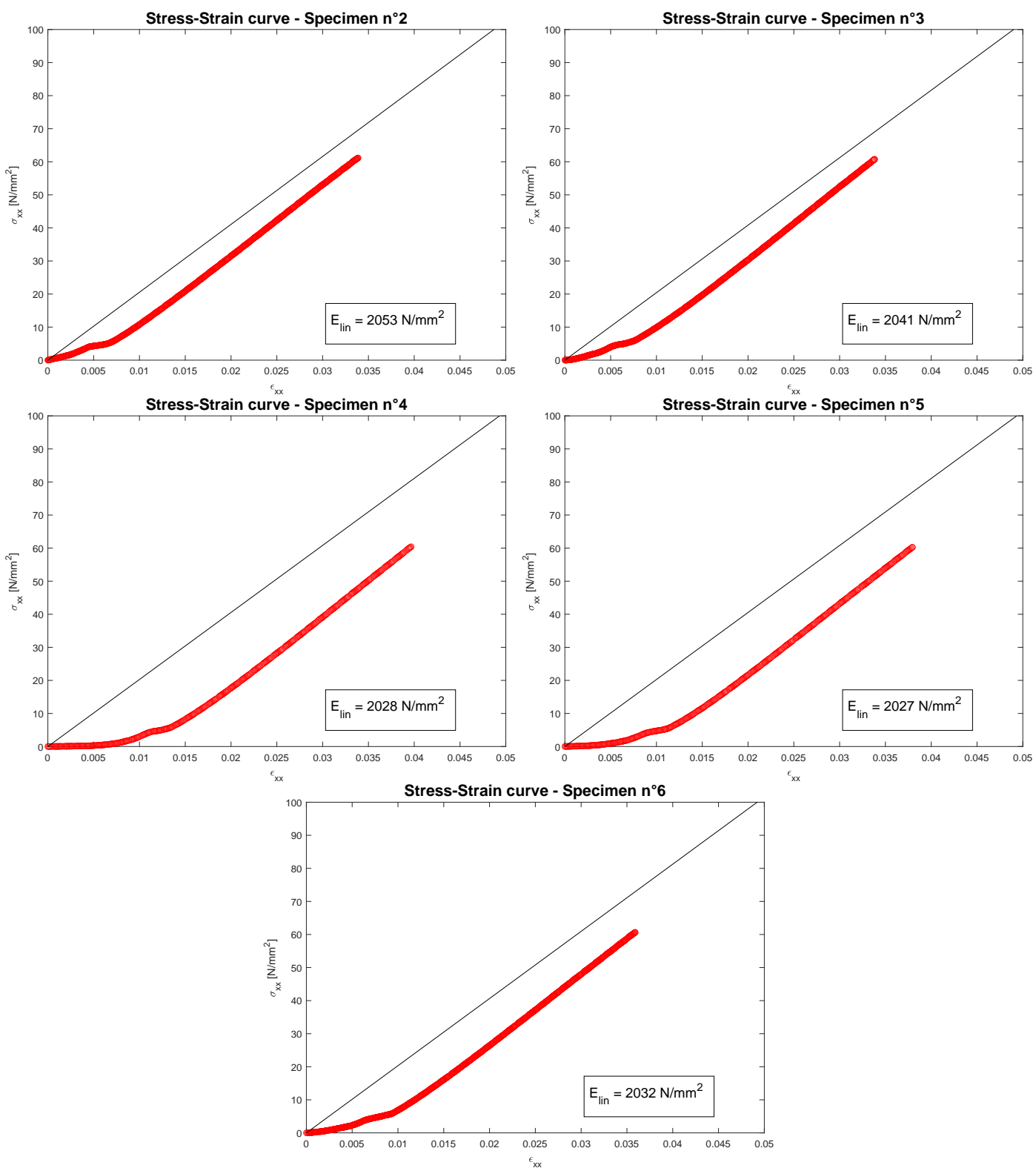

Figure 7. Stress-strain $(\sigma-\epsilon)$ compression test curves for the first 5 specimens of family 1.

\section{Statistical and Capability Analysis}

This section is devoted to the statistical and capability analysis of geometrical and mechanical data for both tensile and compression specimens and related experimental tests. Therefore, this section is organized in four main parts.

\subsection{Geometrical Data of Specimens for Tensile Test}

The main geometrical data of specimens employed for the tensile test are summarized in Table 1 using the grouping in two main families. The values for the $X$ dimension are not given because the length of the reduced section cannot be measured due to the presence of the curvature.

First of all, for an appropriate capability analysis, it is important to understand if the collected data can be represented using a normal distribution [41]. This information is provided in Table 5 and in Figures 9-11 via two indexes defined as AD-value (Anderson Darling value) and the P-value (Probability value). If low values for $\mathrm{AD}$ are calculated, this feature means that the proposed data can be successfully investigated by using a normal distribution, this conclusion can be further validated via the determination of an high value for the P-index (this last one varies from 0 to 1 and it must be 
usually greater than an opportune treshold value, this value has been set equals 0.05 in the present paper). As shown in graphical summaries and probability plots reported in Figures 9-11 and in the AD-value and P-value lines of Table 5, the normality test has been successfully passed by the two dimensions $\mathrm{Y}$ and $\mathrm{Z}$ and also by the weight $\mathrm{W}$. The normal distribution analysis allows the calculation of a mean value $\mu$ and a standard deviation $\hat{\sigma}$. These two parameters have been defined for all the 12 specimens (see the first part of Table 5) giving an overall capability analysis defined in the long period. In the second and third part of Table 5, the capability analysis has been separately performed for the first and second family, each one composed by 6 specimens; this type of analysis is defined as potential or within capability analysis because it is carried out in the short period. By definition, a process is usually more stable in the short period with respect to the long period because in the short period there are fewer dispersion factors in the production process. This conclusion is confirmed for both the dimensions $Y$ and $Z$ and also for the weight $W$ : this feature is clear from the observation of the values for standard deviation $\hat{\sigma}, C_{p}$ and $P_{p}$ proposed in the related tables and figures and also by the observation of the Gaussian curves for overall and within periods proposed in the process capability report shown in Figures 9-11 (the dotted Gauss curve is always higher and narrower than the Gauss curve with a continuous line). The calculation of the mean value $\mu$ and the standard deviation $\hat{\sigma}$ allows the definition of a range between an Upper Specification Limit (USL) and a Lower Specification Limit (LSL). In the present study, a $\hat{\sigma}$-level equals 4 has been imposed and the limits are calculated as $U S L=\mu+4 \hat{\sigma}$ and $L S L=\mu-4 \hat{\sigma}$. This choice gives that the $99.38 \%$ of the next produced specimens should have geometrical dimensions and weights inside the range with limits USL and LSL. These results confirms how the use of the FDM technology for polymeric materials is a good quality process as demonstrated by the successfully use of the $\hat{\sigma}$-level equals 4 .

Table 4. Collected mechanical data obtained from the compression tests conducted on the two families of specimens.

\begin{tabular}{cccc}
\hline Specimen (Family) & $E_{\text {lin }}[\mathrm{MPa}]$ & $\sigma_{\text {max }}[\mathrm{MPa}]$ & $\sigma_{\text {pro }}[\mathrm{MPa}]$ \\
\hline $1(1)$ & - & - & - \\
$2(1)$ & 2053.4 & - & - \\
$3(1)$ & 2041.0 & - & - \\
$4(1)$ & 2027.5 & - & - \\
$5(1)$ & 2026.8 & - & - \\
$6(1)$ & 2031.5 & - & - \\
$7(2)$ & 1990.4 & - & - \\
$8(2)$ & 2093.0 & - & - \\
$9(2)$ & 2048.5 & - & - \\
$10(2)$ & 2016.4 & - & - \\
$11(2)$ & 2033.1 & - & - \\
$12(2)$ & 2023.5 & - & - \\
\hline
\end{tabular}

The dimension $Y$ has a mean value equals $13.0079 \mathrm{~mm}$ with standard deviation equals $0.029637 \mathrm{~mm}$. The $\sigma$-level 4 gives the USL equals $13.1265 \mathrm{~mm}$ and the LSL equals $12.8894 \mathrm{~mm}$. The target value for $Y$ is $13.00 \mathrm{~mm}$; therefore, it is inside the range and very close to the mean value. The target value is smaller than the mean value. These data are already satisfactory but they can be also appropriately used to further improve the printing process of future specimens by opportunely re-scaling the initial draws by using appropriate re-scaling factors obtained from differences in percentage between the target and the mean values.

The dimension $Z$ has a mean value equals $4.9274 \mathrm{~mm}$ with standard deviation equals $0.027820 \mathrm{~mm}$. The $\sigma$-level 4 gives the USL equals $5.0386 \mathrm{~mm}$ and the LSL equals $4.8161 \mathrm{~mm}$. The target value for $Z$ is $5.00 \mathrm{~mm}$, therefore, it is inside the range and very close to the mean value. The target value is greater than the mean value. These data are already satisfactory but they can be also appropriately used to further improve the printing process of future specimens. 

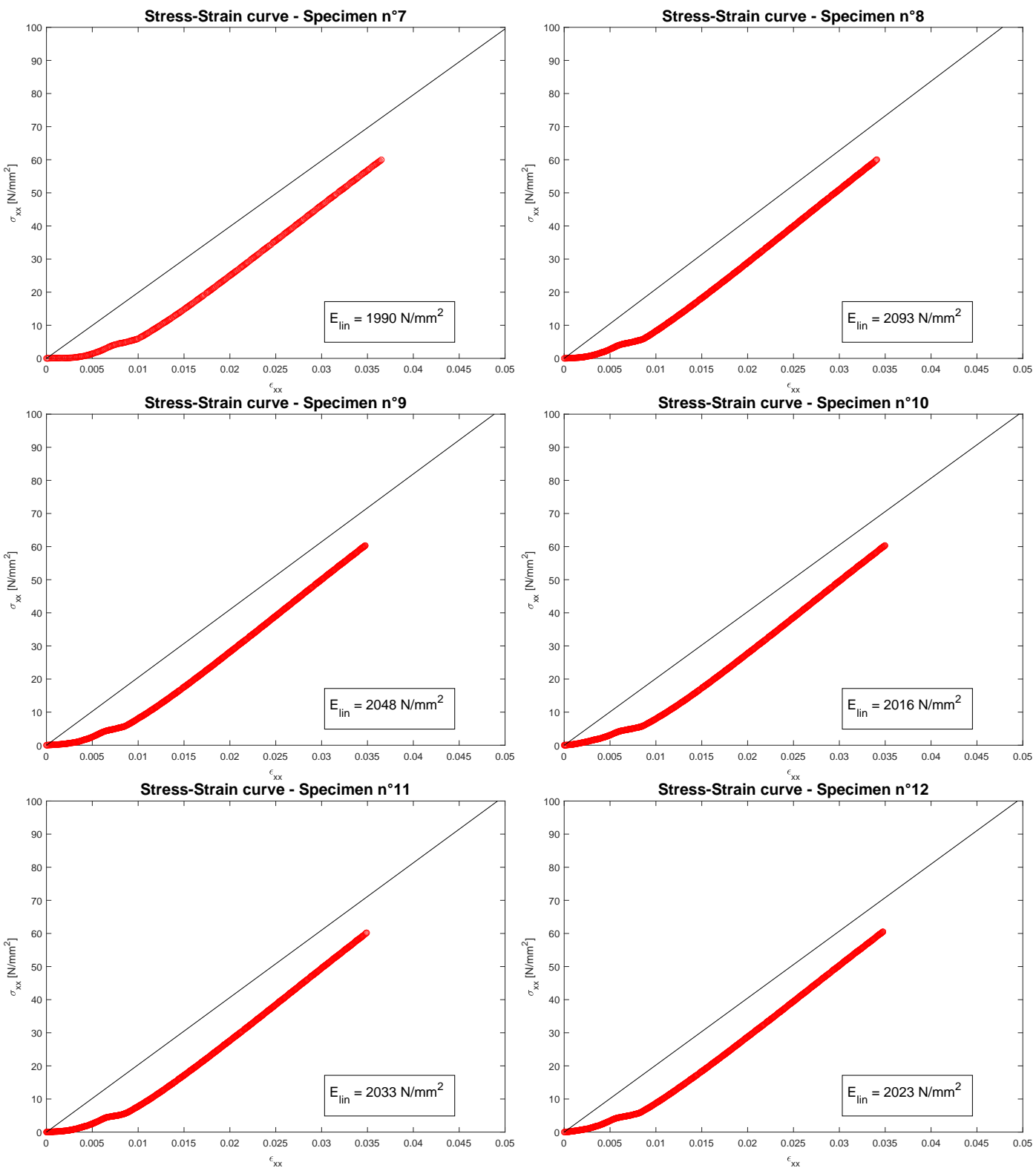

Figure 8. Stress-strain $(\sigma-\epsilon)$ compression test curves for the second 6 specimens of family 2 .

The weight $W$ has a mean value equals $17.9901 \mathrm{~g}$ with standard deviation equals $0.097526 \mathrm{~g}$. Using these data, a $\sigma$-level 4 gives a range with limits $U S L=18.3802 \mathrm{~g}$ and $L S L=17.6000 \mathrm{~g}$. The target value for $\mathrm{W}$ is $18.18 \mathrm{~g}$ and it is inside the range. The weight is not a direct parameter but it derives from the dimensional data $(X, Y$ and $Z$ ) and from the parameters chosen for the printing process. Therefore, the target value is not so close to the mean value (in particular, if compared with the cases already seen for $Y$ and $Z$ ). A further improvement could be obtained using this analysis and the previous considerations already seen for the dimensions $Y$ and $Z$.

The conducted analyses allow the evaluation of the printing process in terms of dimensions of the specimens and their weights. The results seem satisfactory and they can be also useful to further improve the quality of the production of the future specimens for tensile tests. This feature could be also useful to improve the mechanical property results because the tests will be performed on specimens with geometric properties all very similar to each other. 
Table 5. Summary of the capability analysis for the dimensions and weight of the produced specimens for the tensile test.

\begin{tabular}{|c|c|c|c|c|}
\hline & $X$ & $\mathbf{Y}$ & $\mathbf{Z}$ & $\mathbf{W}$ \\
\hline \multicolumn{5}{|c|}{ All the 12 specimens } \\
\hline Mean value $\mu$ & - & 13.0079 & 4.9274 & 17.9901 \\
\hline Stand. dev. $\hat{\sigma}$ & - & 0.029637 & 0.027820 & 0.097526 \\
\hline LSL & - & 12.8894 & 4.8161 & 17.6000 \\
\hline USL & - & 13.1265 & 5.0386 & 18.3802 \\
\hline AD-value & - & 0.369 & 0.313 & 0.223 \\
\hline P-value & - & 0.368 & 0.504 & 0.777 \\
\hline
\end{tabular}

The first six specimens of the family 1

\begin{tabular}{lllll}
\hline Mean value $\mu$ & - & 13.0222 & 4.9461 & 18.0648 \\
Stand. dev. $\hat{\sigma}$ & - & 0.027642 & 0.022002 & 0.055869 \\
\hline \multicolumn{4}{c}{ The second six specimens of the family 2} \\
\hline Mean value $\boldsymbol{\mu}$ & - & 12.9936 & 4.9086 & 17.9154 \\
Stand. dev. $\hat{\sigma}$ & - & 0.026022 & 0.019363 & 0.066369 \\
\hline
\end{tabular}
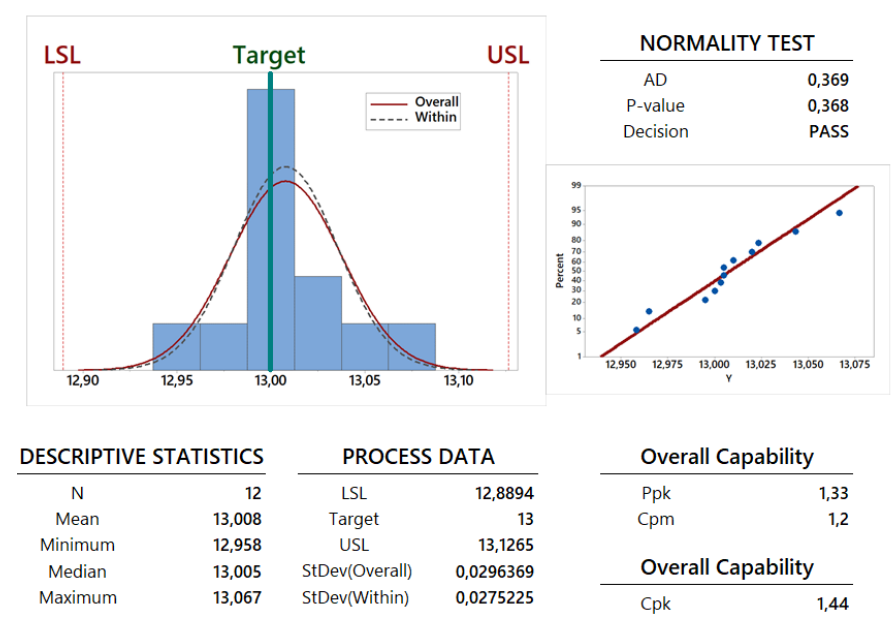

$$
\begin{array}{lr}
\multicolumn{2}{l}{\text { Overall Capability }} \\
\hline \mathrm{Ppk} & 1,33 \\
\mathrm{Cpm} & 1,2 \\
\multicolumn{2}{l}{\text { Overall Capability }} \\
\hline \mathrm{Cpk}
\end{array}
$$

Figure 9. Graphical summary, probability plot and process capability report for the dimension $\mathrm{Y}$ of the 12 produced specimens for tensile test.
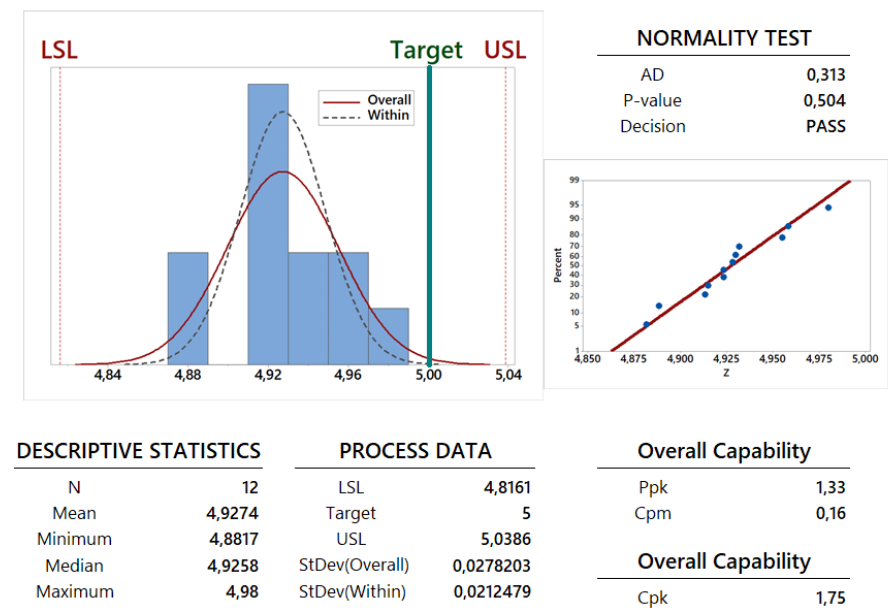

Figure 10. Graphical summary, probability plot and process capability report for the dimension $\mathrm{Z}$ of the 12 produced specimens for tensile test. 


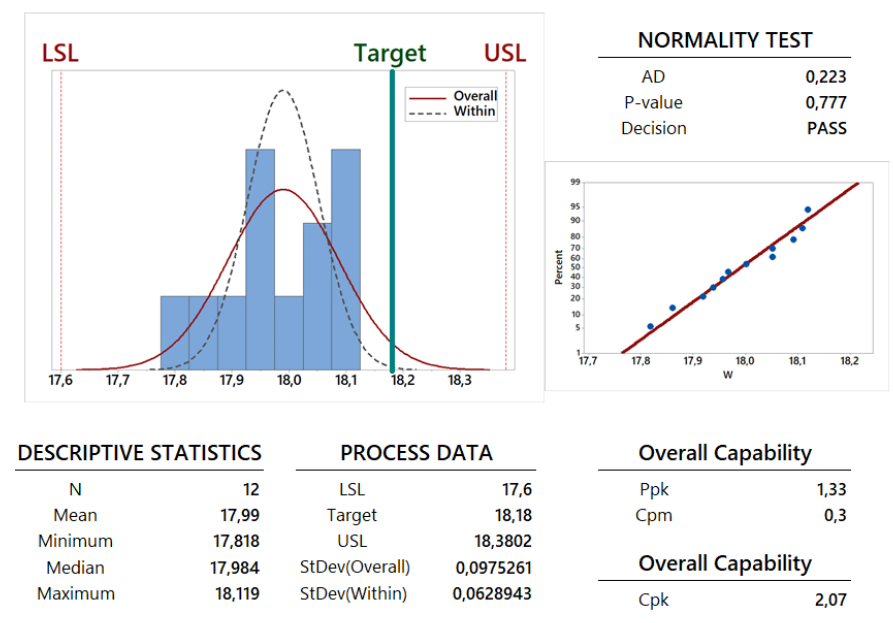

Figure 11. Graphical summary, probability plot and process capability report for the weight W of the 12 produced specimens for tensile test.

\subsection{Geometrical Data of Specimens for Compression Test}

The main geometrical data of specimens used for the compression test have been collected in Table 2 where the families of the printed specimens are clearly indicated. These data will be here used for the appropriate capability analysis [41].

A preliminary study is performed to understand if the capability analysis can be developed using a normal distribution for the collected data. This study is provided using some information shown in Table 6 and in Figures 12-15, the observation of the AD-value and the P-value is fundamental. The graphical summaries and probability plots shown in Figures 12-15 and the AD-value and P-value given in the last two lines of the first part of Table 6 confirm that the normality test has been successfully passed by all the dimension parameters and the weight. Therefore, the Gaussian normal distribution can be employed for such an analysis: a mean value $\mu$ and a standard deviation $\hat{\sigma}$ can be calculated for the dimensions $X, Y$ and $Z$ and for the weight $W$. These two statistical parameters have been calculated for all the 12 specimens in order to perform a capability analysis in the long period (see the first part of Table 6) and for each family composed by 6 specimens in order to perform a potential or within capability analysis carried out in the short period (see the second and third part of Table 6). From a theoretical point of view, a process is usually more stable in the short period with respect to the long period. This feature is confirmed for the dimensions $Y$ and $Z$. On the contrary, the stability in the long period is very similar to the stability in the short period in the cases of dimension $X$ and weight $W$. This last feature comes from the observation of the values for standard deviation $\hat{\sigma}, C_{p}$ and $P_{p}$ proposed in the related tables and figures and also by the observation of the Gaussian curves for overall (curves with a continuous line) and within (dotted curves) periods proposed in the process capability report shown in Figures 12-15.

The dimension $X$ has a mean value equals $39.7975 \mathrm{~mm}$ with standard deviation equals $0.032063 \mathrm{~mm}$. The $\sigma$-level 4 gives the USL equals $39.9258 \mathrm{~mm}$ and the LSL equals $39.6692 \mathrm{~mm}$. The target value for $X$ is $40.00 \mathrm{~mm}$, it is outside the range even if it not so far from the mean value. The target value is greater than the mean value.

The mean value of the dimension $Y$ is $12.4904 \mathrm{~mm}$ with a standard deviation equals $0.039194 \mathrm{~mm}$. By imposing a $\sigma$-level equals 4 , the range has limits $U S L=12.6472 \mathrm{~mm}$ and $L S L=12.3336 \mathrm{~mm}$. The target value equals $12.70 \mathrm{~mm}$ is outside the range and far from the mean value.

The dimension $Z$ has a mean value equals $12.5958 \mathrm{~mm}$ and a standard deviation equals $0.023069 \mathrm{~mm}$. These data have been used with a $\sigma$-level equals 4 to define a range with limits $U S L=12.6881 \mathrm{~mm}$ and $L S L=12.5036 \mathrm{~mm}$. The target value $12.70 \mathrm{~mm}$ is out side this range but it is not so far from the mean value. 
The data calculated for $X, Y$ and $Z$ dimensions could be used to improve the printing process of future specimens by means of an opportune re-scaling of the original draws.

The weight $W$ has a mean value equals $7.7447 \mathrm{~g}$ and a standard deviation equals $0.031206 \mathrm{~g}$. These two parameters employed in a $\sigma$-level 4 analysis give a range with limits $U S L=7.8695 \mathrm{~g}$ and $L S L=7.6198 \mathrm{~g}$. The target value is $8.06 \mathrm{~g}$, it is outside the limits. The weight is not a geometrical and direct parameter because it depends by the specimen dimensions and by the printing process. Therefore, an improvement for this parameter is a cumbersome problem and it also depends on the previous investigated geometrical data.

Table 6. Summary of the capability analysis for the dimensions and weight of the produced specimens for the compression test.

\begin{tabular}{|c|c|c|c|c|}
\hline & $\mathbf{X}$ & $\mathbf{Y}$ & $\mathbf{Z}$ & W \\
\hline \multicolumn{5}{|c|}{ All the 12 specimens } \\
\hline Mean value $\mu$ & 39.7975 & 12.4904 & 12.5958 & 7.7447 \\
\hline Stand. dev. $\hat{\sigma}$ & 0.032063 & 0.039194 & 0.023069 & 0.031206 \\
\hline LSL & 39.6692 & 12.3336 & 12.5036 & 7.6198 \\
\hline USL & 39.9258 & 12.6472 & 12.6881 & 7.8695 \\
\hline AD-value & 0.488 & 0.267 & 0.167 & 0.452 \\
\hline P-value & 0.180 & 0.619 & 0.916 & 0.225 \\
\hline \multicolumn{5}{|c|}{ The first six specimens of the family 1} \\
\hline Mean value $\mu$ & 39.7886 & \multirow{2}{*}{$\begin{array}{l}12.4667 \\
0.026442\end{array}$} & 12.5858 & 7.7335 \\
\hline Stand. dev. $\hat{\sigma}$ & 0.030155 & & 0.026957 & 0.032561 \\
\hline \multicolumn{5}{|c|}{ The second six specimens of the family 2} \\
\hline Mean value $\mu$ & 39.8064 & \multirow{2}{*}{$\begin{array}{l}12.5142 \\
0.036423\end{array}$} & 12.6058 & \multirow{2}{*}{$\begin{array}{l}7.7558 \\
0.027980\end{array}$} \\
\hline Stand. dev. $\hat{\sigma}$ & 0.034098 & & 0.014289 & \\
\hline \multirow[t]{2}{*}{ LSL } & \multicolumn{2}{|r|}{ USL } & \multicolumn{2}{|c|}{ NORMALITY TEST } \\
\hline & \multicolumn{2}{|c|}{$\ldots$ Overall } & $\begin{array}{c}\text { AD } \\
\text { P-value } \\
\text { Decision }\end{array}$ & $\begin{array}{r}0,488 \\
0,18 \\
\text { PASS }\end{array}$ \\
\hline $39,67 \quad 39,71$ & 39,83 & 39,91 & 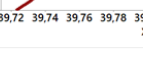 & $239.8439,8639,8$ \\
\hline DESCRIPTIVE STATISTICS & \multicolumn{2}{|c|}{ PROCESS DATA } & \multicolumn{2}{|c|}{ Overall Capability } \\
\hline$\stackrel{N}{N}$ & LSL & 39,6692 & Ppk & 1,33 \\
\hline $\begin{array}{l}\text { Mean } \\
\text { Minimum }\end{array}$ & Target & 40 & $\mathrm{Cpm}$ & \\
\hline $\begin{array}{l}\text { Minimum } \\
\text { Median }\end{array}$ & $\begin{array}{c}\text { USL } \\
\text { StDev(Overall) }\end{array}$ & $\begin{array}{r}39,9258 \\
0,0320629\end{array}$ & Overall C & oability \\
\hline Maximum & StDev(Within) & 0,0330007 & Cpk & 1,3 \\
\hline
\end{tabular}

Figure 12. Graphical summary, probability plot and process capability report for the dimension $X$ of the 12 produced specimens for compression test.

\subsection{Mechanical Properties From Tensile Test}

The mechanical properties obtained from the tensile tests have been grouped in Table 3, the first column gives the tested specimens and in parentheses there is the related family, the second column shows the linear elastic Young modulus for each specimen, the third column gives the ultimate tensile strength and the last column shows the proportional limit stress. These data will be used in this section to perform the appropriate capability analysis [41]. 

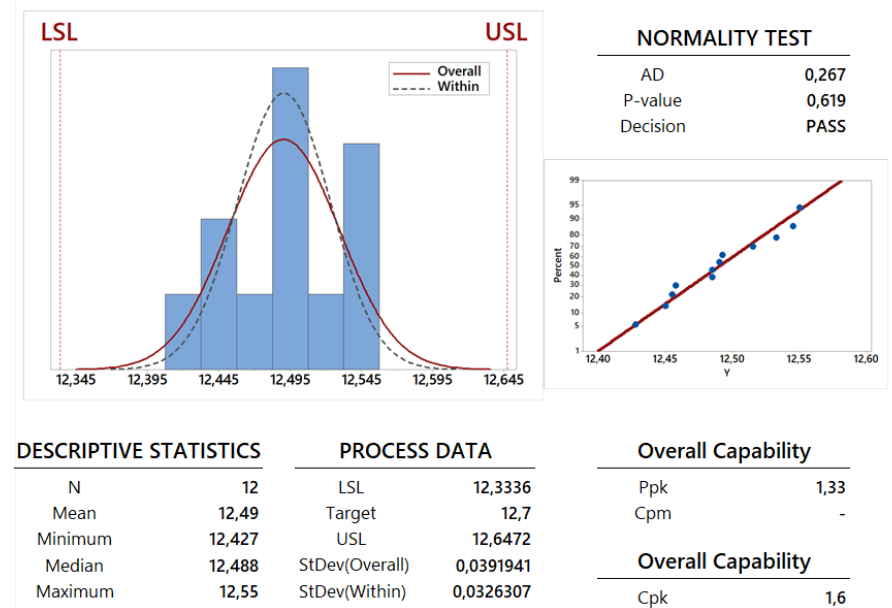

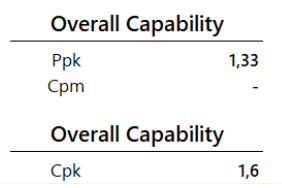

Figure 13. Graphical summary, probability plot and process capability report for the dimension $\mathrm{Y}$ of the 12 produced specimens for compression test.

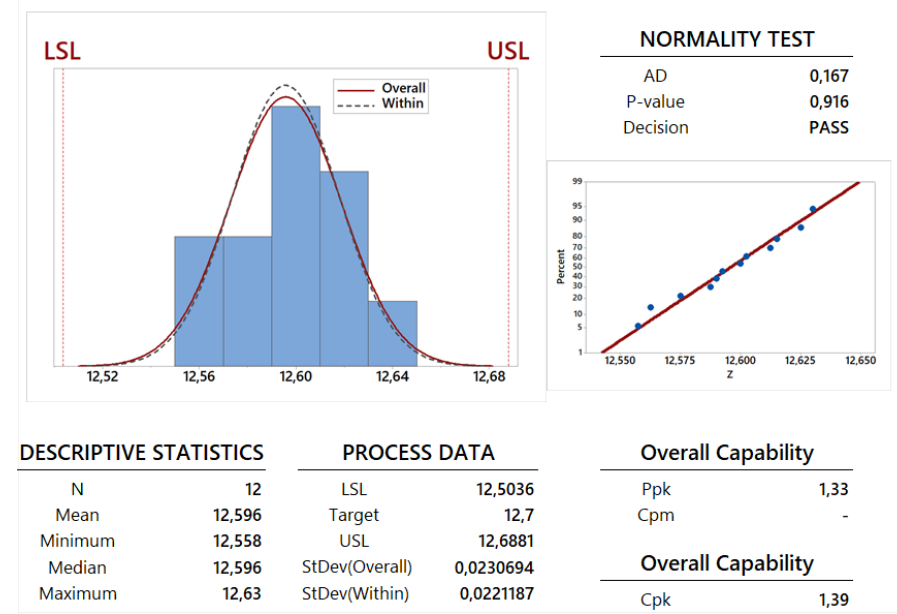

Figure 14. Graphical summary, probability plot and process capability report for the dimension $\mathrm{Z}$ of the 12 produced specimens for compression test.

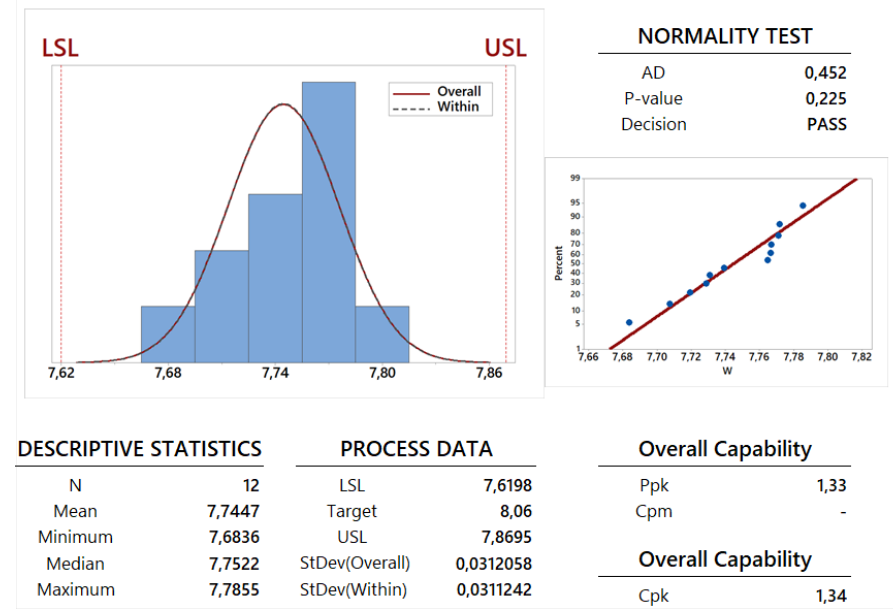

Figure 15. Graphical summary, probability plot and process capability report for the weight $\mathrm{W}$ of the 12 produced specimens for compression test. 
The capability analysis is performed using a normal distribution for the presented data. The correctness of the use of the normal distribution is confirmed by the observation of the AD-values and P-values given in Figures 16-18 (see the related graphical summaries and probability plots) and in the last two lines of the first part of Table 7: all these information confirm that the normality test has been successfully passed by all the mechanical parameters. Therefore, the Gaussian normal distribution can be used for this analysis and a mean value $\mu$ and a standard deviation $\hat{\sigma}$ can be calculated for the linear elastic Young modulus $E_{l i n}$, the ultimate tensile strength $\sigma_{\max }$ and the proportional limit stress $\sigma_{\text {pro }}$. The mean value and the standard deviation have been calculated for all the 12 specimens in order to perform a capability analysis in the long period (see the first part of Table 7). The 12 specimens have been then grouped in two families (each one composed by 6 specimens) in order to perform a potential or within capability analysis carried out in the short period (see the second and third part of Table 7). In general, a process is usually more stable in the short period with respect to the long period. This feature is confirmed for the all the calculated mechanical parameters as clearly shown by the observation of the values for standard deviation $\hat{\sigma}, C_{p}$ and $P_{p}$ proposed in the related tables and figures, and also by the observation of the Gaussian curves for overall and within periods proposed in the process capability report shown in Figures 16-18.

The linear elastic Young modulus $E_{\text {lin }}$ has a mean value equals $2549.0333 \mathrm{MPa}$ with standard deviation equals $100.860861 \mathrm{MPa}$. The $\sigma$-level 4 gives the USL equals 2952.4768 MPa and the LSL equals $2145.5899 \mathrm{MPa}$. This range means that the $99.38 \%$ of future specimens should have a value for the linear elastic Young modulus inside these limits. The USL or the LSL can be used as design values depending on the type of analysis (statics, dynamics and so on). For example, in a static analysis, the LSL can be employed as design value in order to perform a conservative verification. Similar considerations can be made for all the mechanical properties defined in this section. No target values exist for all the proposed mechanical properties because they have been defined in this paper for the first time.

The ultimate tensile strength $\sigma_{\max }$ has a mean value equals $61.4917 \mathrm{MPa}$ and a standard deviation equals 1.684938 MPa. A $\sigma$-level 4 means the USL equals 68.2314 MPa and the LSL equals 54.7519 MPa. The future specimens should have an ultimate tensile strength $\sigma_{\max }$ inside this range in the $99.38 \%$ of the cases. In a structural verification, the LSL can be used as ultimate tensile strength in order to be more conservative as possible.

Table 7. Summary of the capability analysis for the mechanical properties of the specimens subjected to the tensile test.

\begin{tabular}{|c|c|c|c|}
\hline & $E_{\text {lin }}$ & $\sigma_{\max }$ & $\sigma_{\text {pro }}$ \\
\hline \multicolumn{4}{|c|}{ All the 12 specimens } \\
\hline Mean value $\mu$ & 2549.0333 & 61.4917 & 46.6333 \\
\hline Stand. dev. $\hat{\sigma}$ & 100.860861 & 1.684938 & 3.646501 \\
\hline LSL & 2145.5899 & 54.7519 & 32.0473 \\
\hline USL & 2952.4768 & 68.2314 & 61.2193 \\
\hline AD-value & 0.258 & 0.245 & 0.371 \\
\hline P-value & 0.652 & 0.697 & 0.363 \\
\hline \multicolumn{4}{|c|}{ The first six specimens of the family 1} \\
\hline Mean value $\mu$ & 2495.5167 & 62.1000 & 49.4833 \\
\hline Stand. dev. $\hat{\sigma}$ & 76.544717 & 1.638292 & 1.290607 \\
\hline \multicolumn{4}{|c|}{ The second six specimens of the family 2} \\
\hline Mean value $\mu$ & 2602.5500 & 60.8833 & 43.7833 \\
\hline Stand. dev. $\hat{\sigma}$ & 98.222375 & 1.635135 & 2.844937 \\
\hline
\end{tabular}




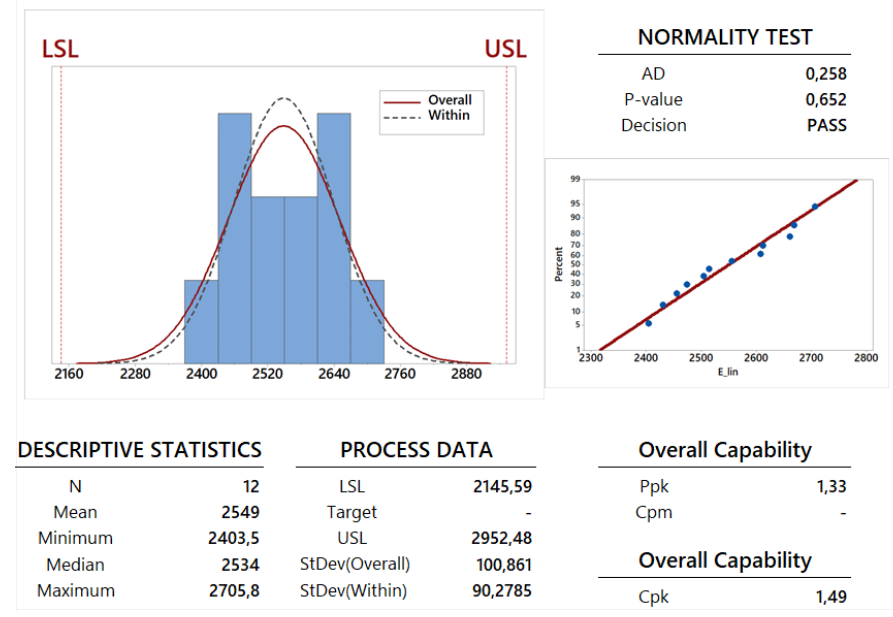

Figure 16. Graphical summary, probability plot and process capability report for the linear elastic Young modulus $E_{\text {lin }}$ of tensile test.

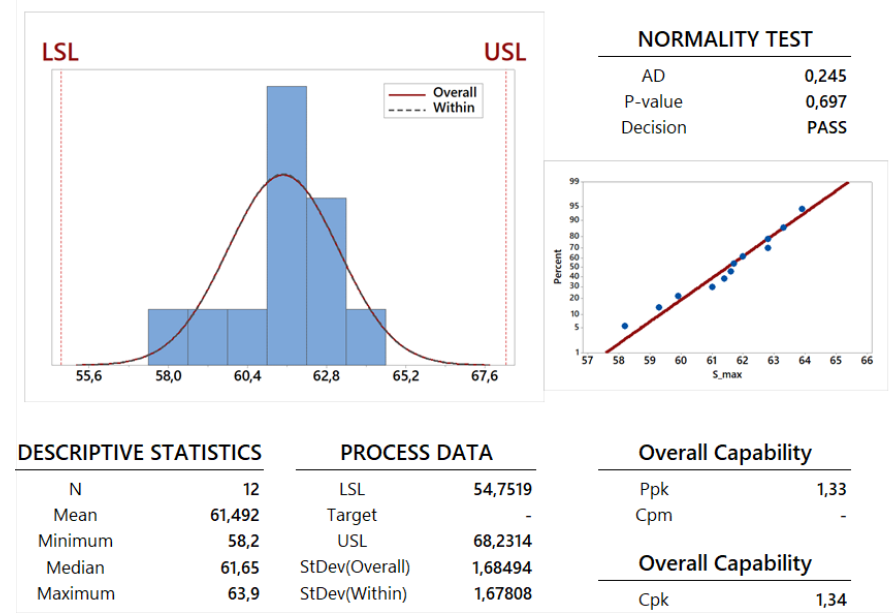

Figure 17. Graphical summary, probability plot and process capability report for the ultimate strength $\sigma_{\max }$ of tensile test.

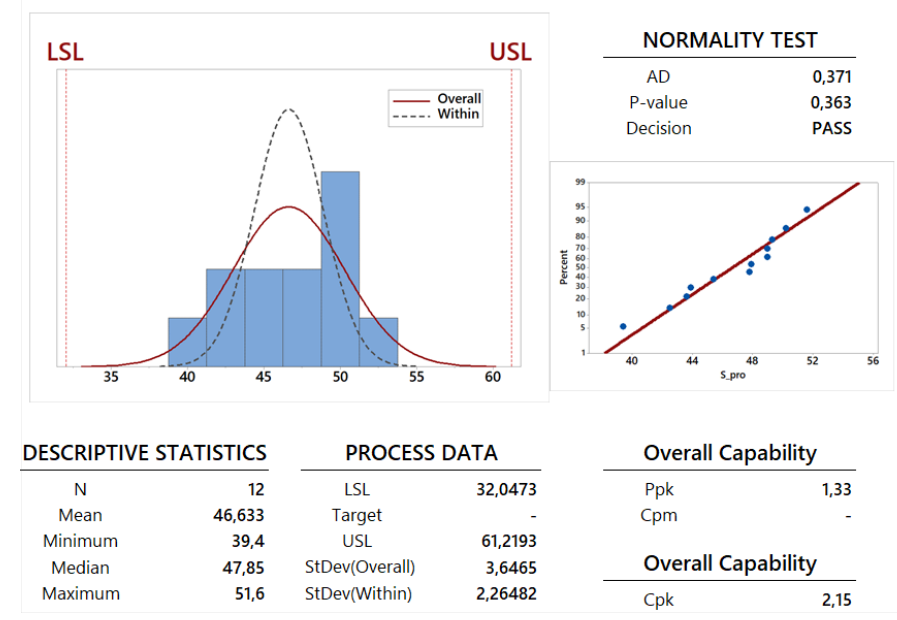

Figure 18. Graphical summary, probability plot and process capability report for the proportional limit stress $\sigma_{\text {pro }}$ of tensile test. 
The proportional limit stress $\sigma_{\text {pro }}$ has a mean value equals $46.6333 \mathrm{MPa}$ with standard deviation equals 3.646501 MPa. The $\sigma$-level 4 gives the USL equals 61.2193 MPa and the LSL equals $32.0473 \mathrm{MPa}$. This range means that the $99.38 \%$ of future specimens should have a value for the proportional limit stress inside these limits.

\subsection{Mechanical Properties From Compression Test}

The mechanical property obtained from the compression tests is only the linear elastic Young modulus $E_{l i n}$ because the tests were stopped when the machine arrived to the maximum applicable load P equals $10 \mathrm{kN}$ : for this maximum value, only a linear elastic region is clearly showed and proportional limit stresses and ultimate tensile strengths cannot be defined in an appropriate way. Therefore, Table 4 shows only the data for the linear elastic Young modulus. Moreover, the first family contains only 5 specimens because the first one did not give correct results in the related compression test. The capability analysis for the linear elastic Young modulus $E_{\text {lin }}$ has been performed using a Gaussian normal distribution because the AD-value and P-value proposed in the graphical summaries and probability plots of Figure 19 and in the last two lines of the first part of Table 8 confirm the validity of this approach for such a set of data. The mean value $\mu$ and the standard deviation $\hat{\sigma}$ have been calculated for all the 11 specimens in order to perform a capability analysis in the long period (see the first part of Table 8) and for each family in order to perform a potential or within capability analysis carried out in the short period (see the second and third part of Table 8). In general, a process is usually more stable in the short period with respect to the long period [41]. This feature is not confirmed by the values for standard deviation $\hat{\sigma}, C_{p}$ and $P_{p}$ proposed in the related table and figure and also by the observation of the Gaussian curves for overall and within periods proposed in the process capability report shown in Figure 19. This inconsistency could be due to the small size of the specimens and the small number of produced and tested specimens.

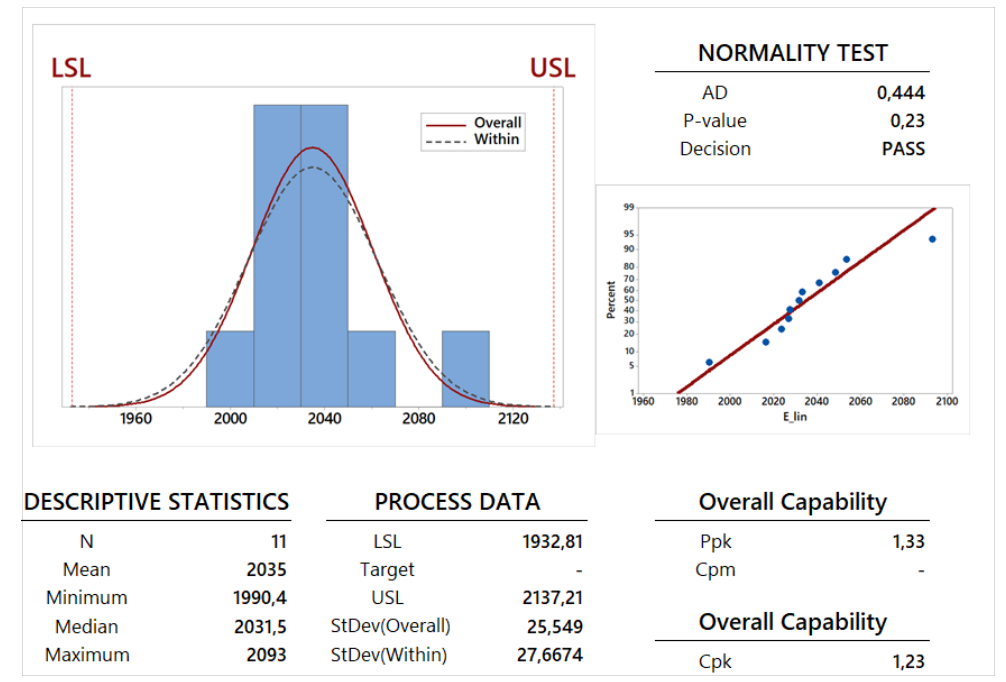

Figure 19. Graphical summary, probability plot and process capability report for the linear elastic Young modulus $E_{\text {lin }}$ of compression test. 
Table 8. Summary of the capability analysis for the mechanical properties of the specimens subjected to the compression test.

\begin{tabular}{ll}
\hline \multicolumn{2}{c}{$E_{\text {lin }}$} \\
\hline \multicolumn{1}{c}{ All the 12 specimens } \\
\hline Mean value $\mu$ & 2035.0091 \\
Stand. dev. $\hat{\sigma}$ & 25.549030 \\
LSL & 1932.8130 \\
USL & 2137.2052 \\
AD-value & 0.444 \\
P-value & 0.230 \\
\hline The first five specimens of the family 1 \\
\hline Mean value $\boldsymbol{\mu}$ & 2036.0400 \\
Stand. dev. $\hat{\sigma}$ & 11.234901 \\
\hline The second six specimens of the family $\mathbf{2}$ \\
\hline Mean value $\mu$ & 2034.1500 \\
Stand. dev. $\hat{\sigma}$ & 34.678221 \\
\hline
\end{tabular}

The linear elastic Young modulus $E_{\text {lin }}$ for the compression behavior has a mean value equals 2035.0091 MPa with standard deviation equals 25.549030 MPa. By comparing results of Table 8 with those of Table 7, it is clear how the PLA elements printed by means of the FDM process have not the same behavior in compression and tensile state. This is a fundamental feature for the design of structural elements made of PLA and produced via FDM. For example, in a buckling analysis, the compressive properties must be used in place of tensile properties in order to obtain correct results. This last point is an important difference with respect to metallic elements produced via classical technologies where no differences are remarked between the compressive and tensile mechanical properties.

By imposing $\sigma$-level equals 4 , the range has limits $L S L=1932.8130 \mathrm{MPa}$ and $U S L=2137.2052 \mathrm{MPa}$. Future printed specimens will have compression linear elastic Young modulus inside these limits in the $99.38 \%$ of the cases. The USL or the LSL can be used as design values depending on the type of compression analysis (statics, dynamics and so on). No target value exists for this mechanical property because it has been defined in this paper for the first time.

\section{Conclusions}

In this paper, the tensile and compression mechanical properties of FDM 3D-printed PLA elements were discussed after appropriate experimental tests. No recognized standards exist for the quantification of the mechanical properties of FDM components. For this reason, the authors used the geometric characteristics for the quantification of mechanical properties of bulk polymers. Therefore, the production process was also investigated. Using the reference dimensions of the produced specimens, the differences between the target and the mean values were remarked via a capability analysis with a sigma-level equals 4 . For each dimension, a range between the USL (Upper Specification Limit) and the LSL (Lower Specification Limit) was showed. The tensile linear elastic modulus, the ultimate tensile stress and the proportional limit stress were identified through a test on a statistically significant sample. The compressive linear elastic modulus was also determined over the same sample-size of the previous test. 3D printed PLA has a non-symmetric behaviour for tensile and compression configurations: in fact, in in-plane loading scenarios, PLA appeared to be less stiff but more resistant in compression. A deep analysis of the obtained mechanical properties was presented; despite a certain scatter of the data, the authors verified their normal distribution and identified the LSL-USL range for the $99.38 \%$ of future components, also proposing design values for different structural analyses (e.g., static and dynamic ones). 
In conclusion, the printing process appears quite stable. In fact, the geometrical target values are often inside the range defined between the USL and the LSL using a $\sigma$-level equals 4 . The geometrical target values are often close to the mean values, the differences in percentage between the target and the mean values can be used in the future to re-scale the CAD draws and, therefore, to improve the printing process quality. In general, no significant differences in terms of standard deviation for geometrical data are shown between specimens for tensile tests and those for compression tests. This feature means that the 3D printing process is satisfactory for both specimen types. From the tensile tests, the mean value for the linear elastic Young modulus is $2549.03 \mathrm{MPa}$, the LSL is $2145.59 \mathrm{MPa}$ and the USL is $2952.48 \mathrm{MPa}$. These values are completely different from those obtained in the compression tests: in these cases, the linear elastic Young modulus is $2035.01 \mathrm{MPa}$ as mean value with LSL equals 1932.81 MPa and USL equals 2137.20 MPa. These data show as the behaviors for tensile and compressive states are completely different and this feature is fundamental when FDM printed elements made of PLA are used as structural parts. In the case of tensile tests, the ultimate strength and the proportional limit stress have been also defined in terms of means values and standard deviations. Therefore, the ultimate strength has a mean value equals $61.4917 \mathrm{MPa}$ with $\mathrm{LSL}=54.7519 \mathrm{MPa}$ and $\mathrm{USL}=68.2314 \mathrm{MPa}$; the proportional limit has a mean value equals $46.6333 \mathrm{MPa}$ with limits equal to $\mathrm{LSL}=32.0473 \mathrm{MPa}$ and USL $=61.2193 \mathrm{MPa}$. Such values were not defined in the case of compression tests because the related specimens are more resistent and the test machine arrived to the maximum applicable load only defining the linear compressive Young modulus. The tensile and compressive mechanical characteristics of FDM printed PLA elements will be fundamental in the future design structural analyses.

Author Contributions: Conceptualization, S.B. and R.T.; methodology, S.B. and R.T.; software, S.B. and R.T.; validation, S.B. and R.T.; investigation, S.B. and R.T.; writing—original draft preparation, S.B. and R.T.; writing-review and editing, S.B. and R.T. All authors have read and agreed to the published version of the manuscript.

Funding: This research received no external funding.

Acknowledgments: Some of the experimental tests were conducted within the course "Design and additive manufacturing for aerospace applications".

Conflicts of Interest: The authors declare no conflict of interest.

\section{References}

1. Levy, G.N.; Schindel, R.; Kruth, J.P. Rapid manufacturing and rapid tooling with Layer Manufacturing (LM) technologies, state of the art and future perspectives. CIRP Ann. 2003, 52, 589-609. [CrossRef]

2. Lu, B.; Li, D.; Tian, X. Development trends in additive manufacturing and 3D printing. Engineering 2015, 1, 85-89. [CrossRef]

3. Carlier, E.; Marquette, S.; Peerboom, C.; Denis, L.; Benali, S.; Raquez, J.M.; Amighi, K. Investigation of the parameters used in fused deposition modeling of Poly (Lactic Acid) to optimize 3D printing sessions. Int. J. Pharm. 2019, 565, 367-377. [CrossRef] [PubMed]

4. Raj, S. A.; Muthukumaran, E.; Jayakrishna, K. A case study of 3D printed PLA and its mechanical properties. Mater. Today Proc. 2018, 5, 11219-11226. [CrossRef]

5. Mohd Pu'ad, N.A.S.; Abdul Haq, R.H.; Mohd Noh, H.; Abdullah, H.Z.; Idris, M.I.; Lee, T.C. Review on the fabrication of fused deposition modelling (FDM) composite filament for biomedical applications. Mater. Today Proc. 2020, 29, 228-232. [CrossRef]

6. Dana, H.R.; Barbe, F.; Delbreilh, L.; Azzouna, M.B.; Guillet, A.; Breteau, T. Polymer additive manufacturing of ABS structure: influence of printing direction on mechanical properties. J. Manuf. Process. 2019, 44, 288-298. [CrossRef]

7. Jiang, H.; Ziegler, H.; Zhang, Z.; Meng, H.; Chronopoulos, D.; Chen, Y. Mechanical properties of 3D printed architected polymer foams under large deformation. Mater. Des. 2020, 194, 108946. [CrossRef]

8. Elmrabet, N.; Siegkas, P. Dimensional considerations on the mechanical properties of 3D printed polymer parts. Polym. Test. 2020, 90, 106656. [CrossRef] 
9. Dizon, J.R.C.; Espera, A.H., Jr.; Chen, Q.; Advincula, R.C. Mechanical characterization of 3D-printed polymers. Addit. Manuf. 2018, 20, 44-67. [CrossRef]

10. Duty, C.; Ajinjeru, C.; Kishore, V.; Compton, B.; Hmeidat, N.; Chen, X.; Liu, P.; Hassen, A.A.; Lindahl, J.; Kunc, V. What makes a material printable? A viscoelastic model for extrusion-based 3D printing of polymers. J. Manuf. Process. 2018, 35, 526-537. [CrossRef]

11. El Moumen, A.; Tarfaoui, M.; Lafdi, K. Additive manufacturing of polymer composites: processing and modeling approaches. Compos. Part B Eng. 2019, 171, 166-182. [CrossRef]

12. Gebisa, A.W.; Lemu, H.G. Influence of 3D printing FDM process parameters on tensile property of ULTEM 9085. Procedia Manuf. 2019, 30, 331-338. [CrossRef]

13. Harshitha, V.; Rao, S.S. Design and analysis of ISO standard bolt and nut in FDM 3D printer using PLA and ABS materials. Mater. Today Proc. 2019, 19, 583-588. [CrossRef]

14. Lay, M.; Thajudin, N.L.N.; Hamid, Z.A.A.; Rusli, A.; Abdullah, M.K.; Shuib, R.K. Comparison of physical and mechanical properties of PLA, ABS and Nylon 6 fabricated using fused deposition modeling and injection molding. Compos. Part B Eng. 2019, 176, 107341. [CrossRef]

15. Mishra, P. K.; Senthil, P. Prediction of in-plane stiffness of multi-material 3D printed laminate parts fabricated by FDM process using CLT and its mechanical behaviour under tensile load. Mater. Today Commun. 2020, 23, 100955. [CrossRef]

16. Heidari-Rarani, M.; Rafiee-Afarani, M.; Zahedi, A.M. Mechanical characterization of FDM 3D printing of continuous carbon fiber reinforced PLA composites. Compos. Part B Eng. 2019, 175, 107147. [CrossRef]

17. Parandoush, P.; Lin, D. A review on additive manufacturing of polymer-fiber composites. Compos. Struct. 2017, 182, 36-53. [CrossRef]

18. Popescu, D.; Zapciu, A.; Amza, C.; Baciu, F.; Marinescu, R. FDM process parameters influence over the mechanical properties of polymer specimens: A review. Polym. Test. 2018, 69, 157-166. [CrossRef]

19. Sagias, V.D.; Giannakopoulos, K.I.; Stergiou, C. Mechanical properties of 3D printed polymer specimens. Struct. Integr. Procedia 2018, 10, 85-90. [CrossRef]

20. Sarvestani, H.Y.; Akbarzadeh, A.H.; Niknam, H.; Hermenean, K. 3D printed architected polymeric sandwich panels: energy absorption and structural performance. Compos. Struct. 2018, 200, 886-909. [CrossRef]

21. Song, Y.; Li, Y.; Song, W.; Yee, K.; Lee, K.Y.; Tagarielli, V.L. Measurements of the mechanical response of unidirectional 3D-printed PLA. Mater. Des. 2017, 123, 154-164. [CrossRef]

22. Sugiyama, K.; Matsuzaki, R.; Ueda, M.; Todoroki, A.; Hirano, Y. 3D printing of composite sandwich structures using continuous carbon fiber and fiber tension. Compos. Part A Appl. Sci. 2018, 113, 114-121. [CrossRef]

23. Valino, A.D.; Dizon, J.R.C.; Espera, A.H., Jr.; Chen, Q.; Messman, J.; Advincula, R.C. Advances in 3D printing of thermoplastic polymer composites and nanocomposites. Prog. Polym. Sci. 2019, 98, 101162. [CrossRef]

24. Wang, X.; Jiang, M.; Zhou, Z.; Gou, J.; Hui, D. 3D printing of polymer matrix composites: a review and prospective. Compos. Part B Eng. 2017, 110, 442-258. [CrossRef]

25. Yadav, D.; Chhabra, D.; Gupta, R.K.; Phogat, A.; Ahlawat, A. Modeling and analysis of significant process parameters of FDM 3D printer using ANFIS. Mater. Today Proc. 2020, 21, 1592-1604. [CrossRef]

26. Yao, T.; Deng, Z.; Zhang, K.; Li, S. A method to predict the ultimate tensile strength of 3D printing PolyLactic Acid (PLA) materials with different printing orientations. Compos. Part B Eng. 2019, 163, 393-402. [CrossRef]

27. Zhao, Y.; Chen, Y.; Zhou, Y. Novel mechanical models of tensile strength and elastic property of FDM AM PLA materials: experimental and theoretical analyses. Mater. Des. 2019, 181, 108089. [CrossRef]

28. Afrose, M.F.; Masood, S.H.; Iovenitti, P.; Nikzad, M.; Sbarski, I. Effects of part build orientations on fatigue behaviour of FDM-processed PLA material. Progr. Addit. Manuf. 2016, 1, 21-28. [CrossRef]

29. Hassanifard, S.; Hashemi, S.M. On the strain-life fatigue parameters of additive manufactured plastic materials through fused filament fabrication process. Addit. Manuf. 2020, 32, 100973. [CrossRef]

30. Ziemian, C. W.; Ziemian, R.D. Residual strength of additive manufactured ABS parts subjected to fatigue loading. Int. J. Fatig. 2020, 134, 105455. [CrossRef]

31. Torres, J.; Cotelo, J.; Karl, J.; Gordon, A.P. Mechanical property optimization of FDM PLA in shear with multiple objectives. J. Min. Met. Mat. Soc. 2015, 67, 1183-1193. [CrossRef]

32. Berzal, M.; Barajas, C.; del Mazo, D.; Caja, J.; Maresca, P. Simple filling patterns to model mechanical behaviour of FDM's test pieces under torsion. Proc. Manuf. 2017, 13, 786-793. [CrossRef] 
33. Brischetto, S.; Maggiore, P.; Ferro, C.G. Additive Manufacturing Technologies and Applications. In Printed Edition of the Special Issue Published in Technologies; MDPI AG: Basel, Switzerland, 2017; p. 180, ISBN 978-3-03842-548-9.

34. Yang, L.; Harrysson, O.; West, H.; Cormier, D. Mechanical properties of 3D re-entrant honeycomb auxetic structures realized via additive manufacturing. Int. J. Solids Struct. 2015, 69-70, 475-490. [CrossRef]

35. Bici, M.; Brischetto, S.; Campana, F.; Ferro, C.G.; Seclì, C.; Varetti, S.; Maggiore, P.; Mazza, A. Development of a multifunctional panel for aerospace use through SLM additive manufacturing. Procedia CIRP 2018, 67, 215-220. [CrossRef]

36. Brischetto, S.; Ciano, A.; Ferro, C.G. A multipurpose modular drone with adjustable arms produced via the FDM additive manufacturing process. Curved Layer. Struct. 2016, 3, 202-213. [CrossRef]

37. Brischetto, S.; Ferro, C.G.; Torre, R.; Maggiore, P. Tensile and compression characterization of 3D printed ABS specimens for UAV applications. In Proceedings of the 3rd International Conference on Mechanical Properties of Materials (ICMPM 2016), Venice, Italy, 14-17 December 2016.

38. Brischetto, S.; Ciano, A.; Raviola, A. Patent Application “Multipurpose Modular Drone with Adjustable Arms". Patent Application 102,015,000,069,620, 5 November 2015.

39. Brischetto, S.; Ferro, C.G.; Maggiore, P.; Torre, R. Compression tests of ABS specimens for UAV components produced via the FDM technique. Technologies 2017, 5, 1-25.

40. Ferro, C.G.; Brischetto, S.; Torre, R.; Maggiore, P. Characterization of ABS specimens produced via the 3D printing technology for drone structural components. Curved Layer. Struct. 2016, 3, 172-188. [CrossRef]

41. Brischetto, S.; Torre, R.; Ferro, C.G. Experimental evaluation of mechanical properties and machine process in Fused Deposition Modelling printed polymeric elements. In Proceedings of the AHFE 2019 International Conference on Additive Manufacturing, Modeling Systems and 3D Prototyping, Washington, DC, USA, 24-28 July 2019; pp. 377-389.

42. Brischetto, S.; Ferro, C.G.; Torre, R.; Maggiore, P. 3D FDM production and mechanical behavior of polymeric sandwich specimens embedding classical and honeycomb cores. Curved Layer. Struct. 2018, 5, 80-94. [CrossRef]

43. Ferro, C.G.; Brischetto, S.; Maggiore, P.; Torre, R. Multi-material sandwich panel produced with desktop 3D printer. In Proceedings of the Mechcomp 3-3rd International Conference of Mechanics of Composites, Bologna, Italy, 4-7 July 2017.

44. ASTM D638-14. Standard Test Method for Tensile Properties of Plastics; ASTM International: West Conshohocken, PA, USA, 2014. Available online: www.astm.org (accessed on 18 September 2020). [CrossRef]

45. ASTM D695-15. Standard Test Method for Compressive Properties of Rigid Plastics; ASTM International: West Conshohocken, PA, USA, 2015. Available online: www.astm.org (accessed on 18 September 2020). [CrossRef]

(C) 2020 by the authors. Licensee MDPI, Basel, Switzerland. This article is an open access article distributed under the terms and conditions of the Creative Commons Attribution (CC BY) license (http:// creativecommons.org/licenses/by/4.0/). 